\title{
La reforma neocolonial de la plaza de Armas. Modernización urbana y patrimonio arquitectónico en Lima, 1901-1952*
}

\author{
HORACIO RAMOS \\ Pontificia Universidad Católica del Perú \\ horacio.ramos@pucp.edu.pe
}

\section{RESUMEN}

Este ensayo muestra cómo los debates en torno a la reforma neocolonial de la plaza de Armas de Lima (1940-1952) propiciaron un cambio en las percepciones sobre modernización urbana y patrimonio arquitectónico en la ciudad. Repasar los proyectos presentados desde inicios del siglo XX permite comprender que la reforma se enmarcó en una linea de intervenciones urbanas que implicaron la destrucción de arquitectura tradicional y la construcción de grandes avenidas y edificios. El ataque de los promotores del funcionalismo contra la reforma produjo que ese tipo de intervenciones y el estilo neocolonial pasen a ser percibidos como "anacrónicos».

Palabras clave: neocolonial, modernismo, patrimonio, Emilio Harth-terré, Agrupación Espacio

* La investigación para este ensayo fue realizada en el marco de mi tesis de maestría en Historia del Arte. Reitero aquí mi agradecimiento a quienes me ofrecieron valiosas críticas y sugerencias durante y después del proceso de su escritura: Juan Carlos Estenssoro, Gabriel Ramón, Dorota Biczel, Adolfo Córdova, Ricardo Kusunoki, Marcos Alarcón, Fernando Villegas, Lev Maciel y, especialmente, Natalia Majluf. Agradezco además a Miguel Cruchaga Belaunde, editor de la versión digital de El Arquitecto Peruano, por permitirme reproducir una imagen publicada en dicha revista, y a Adolfo Córdova por autorizar la reproducción de sus caricaturas. 
ABSTRACT

This essay illustrates how the debates surrounding the neo-colonial redevelopment of Lima's Plaza de Armas (1940-1952) altered perceptions of the city's urban modernization and architectural heritage. Analyzing projects dating back to the turn of the 20th century reveals that the redevelopment was part of a series of urban interventions involving the destruction of architectural heritage and the construction of major avenues and buildings. The promoters of functionalism criticized the redevelopment, prompting to conceive that type of urban intervention and the colonial style as "anachronistic".

Keywords: neo-colonial, modernism, patrimony, Emilio Harth-terré, Agrupación Espacio

E 1948 , el arquitecto Adolfo Córdova publicó en el diario El
Comercio una caricatura que criticaba la reforma de la plaza de Armas de Lima (Fig. 1). ${ }^{1}$ Su trazo sintético, sumado a la ausencia de personas y al ritmo reiterativo de los edificios representados daba a la composición un tono árido. El título de la viñeta, «La balconización de la Plaza de Armas», hacía más explícita la crítica contra una intervención urbana cuyo rasgo más distintivo parecía ser sus desproporcionados balcones que imitaban ostentosamente modelos coloniales. En otra caricatura en la misma página, Córdova continuaba su argumentación visual. Un gigante caminaba junto a los mismos, mientras que una mujer de tamaño normal le decía a su amiga: "Asegura que los balcones son hechos a su medida» (Fig. 2).

La reforma criticada por Córdova tuvo lugar entre 1940 y 1952 e implicó la destrucción de los portales coloniales de piedra de la plaza ${ }^{2}$ y la construcción en su lugar de edificios neocoloniales de cemento.

1 En este ensayo se ha optado por emplear el término «reforma» para aludir a la intervención de los portales, pese a que en la época también se habló de «remodelación», «modernización» y «embellecimiento». La palabra «reforma» sirve mejor para describir un proceso que reconfiguró, y no solo alteró parcialmente, la plaza.

2 Los portales de Escribanos y Botoneros fueron construidos hacia 1692. Véase Emilio Harth-terré, «Notas sobre Lima 1940-1960», The Latin American Library, Universidad 
El diseño de Emilio Harth-terré y José Álvarez Calderón fue elegido por concurso público en 1939, pero desde 1901 distintas propuestas para modernizar la plaza ya habían aparecido en la prensa y más de una polémica fue sostenida sobre qué estilo debía usarse para tal fin. Lo que no se discutió, sino que se aceptó como natural, fue el supuesto de que había que demoler los portales.

La paradoja que implicaba destruir patrimonio colonial para reemplazarlo por edificios que lo evoquen cobró presencia mediática con las caricaturas de Córdova y los artículos que solían acompañarlas, escritos en su mayoría por el intelectual y arquitecto Luis Miró Quesada Garland. Córdova y Miró Quesada publicaron sus críticas contra la reforma en la columna semanal de la Agrupación Espacio, ${ }^{3}$ grupo activo entre 1947 y 1955 que dedicó parte importante de sus esfuerzos a la difusión y posicionamiento de la arquitectura funcionalista y la pintura abstracta en Lima. A diferencia de intentos anteriores por «actualizar» la escena artística, Espacio contó con una inusitada presencia pública, tanto por reunir a agentes culturales de distintos campos, como el pintor Fernando de Szyszlo y el escritor Sebastián Salazar Bondy, como por aprovechar las páginas del diario más importante del país, propiedad de la familia Miró Quesada.

Más allá del tono de burla, la crítica de Espacio contra la reforma tuvo un argumento de fondo: su diseño y tamaño no respondían a una función arquitectónica, como lo exigía el discurso funcionalista, sino a una afición «romántica» $\mathrm{y}$ «anacrónica». Tal situación fue parodiada por Córdova en otra caricatura, «El jarterrorismo, la arquitectura y el amor» (Fig. 3). Ahí, un hombre, como Romeo, subía por una escalera para visitar a su amada, solo para chocar contra una ventana ciega. Este tipo de ventanas eran comunes en la arquitectura historicista del periodo y no cumplían más función que la de dar simetría decorativa a la fachada. El edificio en cuestión existía: era uno de los nuevos portales neocoloniales de la plaza de Armas.

de Tulane, Harth-terré Collection, Manuscritos, caja 2, folder 13. Este archivo contiene fotografías y notas tomadas entre las décadas de 1920 y 1960.

3 Para un inventario de todas las columnas de Espacio, véase Alegre 2001. 


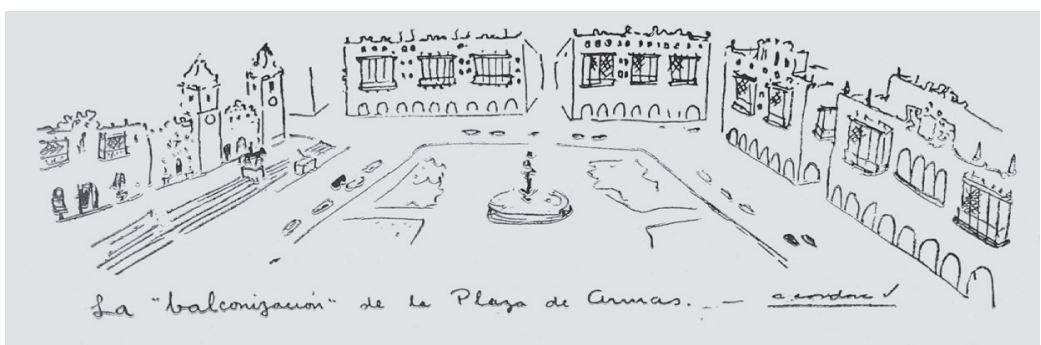

Figura 1. Adolfo Córdova, «La balconización de la Plaza de Armas» (Miró Quesada 1948a).

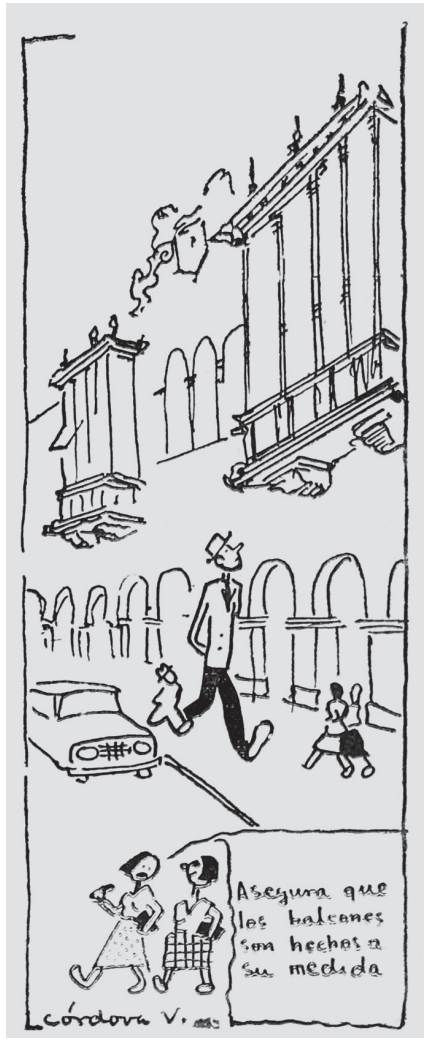

Figura 2. Adolfo Córdova, «Asegura que los balcones son hechos a su medida» (Miró Quesada 1948a).

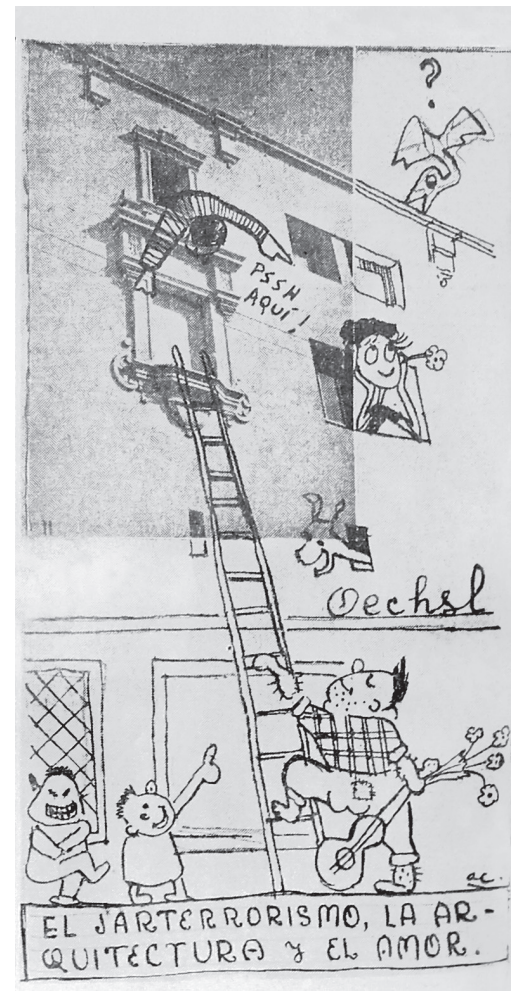

Figura 3. Adolfo Córdova, «El jarterrorismo, la arquitectura y el amor» (Córdova 1949). 
La viñeta proponía un argumento adicional y más punzante contra la reforma. El término «jarterrorismo» fue acuñado por Córdova y empleado por los miembros de Espacio para referirse a las destructivas remodelaciones de edificios tradicionales realizadas por Emilio Harthterré, uno de los primeros y más influyentes arquitectos titulados en el Perú. Durante la década de 1920, este estudió y fotografió la arquitectura de diversas regiones del país, lo cual sustentó su producción como historiador e inspiró su trabajo como arquitecto y restaurador. ${ }^{4}$ En todos estos emprendimientos, Harth-terré mantuvo la convicción de que la arquitectura colonial podía servir de inspiración para la vida moderna y para la construcción de «nuevos símbolos nacionales». No sorprende que al comentar su diseño de reforma para la plaza la describiera como una propuesta de "modernidad tradicional». 5

Con caricaturas y artículos, Espacio refutó ese orden de ideas. Aún más, su caracterización de la reforma como "anacrónica», "colonialista» y «aristocrática» se hizo extensible también a Harth-terré y al estilo neocolonial en general. Tales alegatos no solo fueron coherentes con su ideario, sino que además permitían a sus miembros reservar para sí los apelativos de «modernos» y «socialmente comprometidos». Pese al tiempo transcurrido, las afirmaciones de Espacio contra la reforma, el neocolonial y Harth-terré siguen influyendo en la historiografía y la crítica de la arquitectura.

Aunque mencionada a menudo, la reforma solo ha merecido un estudio académico, el cual recoge las opiniones de renombrados arquitectos; entre ellos, Miró Quesada Garland, quien destacó ahí el carácter «neo-colonialista» de la reforma, y Frederick Cooper Llosa, arquitecto

${ }^{4}$ Harth-terré fue el primer egresado (1919) y titulado (1924) de la Sección de Arquitectos de la Escuela de Ingenieros de Lima (Álvarez 2006: 79). La construcción de su apellido compuesto — con minúscula para el segundo apellido — es inusual, pero fue la que él prefirió («La acusación de vetusto» 1946). Sobre su producción como arquitecto, urbanista y restaurador, véase Pinillos y Pinillos 1982. Sobre su producción historiográfica, Lizárraga y Benavente 1982.

5 Sobre la idea de los «nuevos símbolos», véase Harth-terré 1945. Sobre la idea de «modernidad tradicional», Harth-terré 1971: 31. 
de una generación posterior quien la describió como un «anacronismo cultural». ${ }^{6}$ Otras referencias tangenciales en estudios panorámicos sobre arquitectura del XX interpretaron la reforma como ejemplo de aquella «entelequia» $\mathrm{y}$ «homenaje a lo falso» que habría sido el neocolonial. ${ }^{7} \mathrm{El}$ neocolonial como estilo mantiene también una imagen negativa en la historiografía. Partiendo de una descripción crítica del arquitecto José García Bryce, Sebastián Salazar Bondy lo redujo a una manifestación de la nociva «arcadia colonial» en su influyente Lima, la horrible. ${ }^{8}$ Desde los setenta, tal percepción ha sido enlazada con argumentaciones de filiación marxista, que enfatizaron su supuesto carácter aristocrático y políticamente conservador. ${ }^{9}$ La imagen negativa se extiende hasta el presente. En su reciente y pionero estudio sobre patrimonio arquitectónico del siglo XX, José Hayakawa descalificó las reformas neocoloniales y afirmó que no sería hasta la aparición de Espacio que la restauración cobraría un carácter "científico» en el Perú. ${ }^{10}$

Analizar los proyectos para la plaza permite comprender que, lejos de ser un síntoma extraño en la historia de los espacios públicos limeños, la reforma neocolonial se enmarcó en una línea de propuestas de modernización urbana que implicaron la destrucción de arquitectura tradicional y la construcción de grandes avenidas y edificios. El caso sí fue singular en tanto marcó un punto de inflexión en las percepciones sobre patrimonio arquitectónico. Luego de la polémica generada hacia el final de la reforma, la práctica de demoler construcciones coloniales pasó a ser censurada por la opinión pública, a la vez que el uso de formas coloniales para edificios modernos perdió credibilidad. Este ensayo

6 Abad y Cárdenas 1975. Para un estado de la cuestión sobre artículos en prensa y monografías académicas dedicadas a la plaza, véase Ramos 2014: 11-23.

7 Amaral 1994: 14. Véanse también García Bryce 1980: 145 y ss.; y Gutiérrez 1998: 128.

8 García Bryce 1959: 38-40; Salazar Bondy 2002: 40 y ss., 96.

9 Véase, entre muchos ejemplos, Rodríguez Cobos 1983: 37-60. Un estado de la cuestión sobre la historiografía del neocolonial peruano en Ramos 2014:11-23. Para un estudio del caso mexicano, que muestra cómo la influencia del modernismo funcionalista ha propiciado una percepción historiográfica negativa del neocolonial en dicho país, Lozoya 2010: 122-127.

${ }^{10}$ Hayakawa 2010: 26, 113. 
argumenta que la aparición y posicionamiento del funcionalismo tuvo un rol crucial dentro de tal cambio de percepciones sobre modernización urbana y patrimonio arquitectónico. ${ }^{11}$ La campaña contra la reforma de la plaza de Armas llevada a cabo por arquitectos funcionalistas durante años (Figs. 1-4, 12) sirvió para desacreditar al neocolonial, a la vez que le otorgó al funcionalismo un rol prominente en la escena limeña.

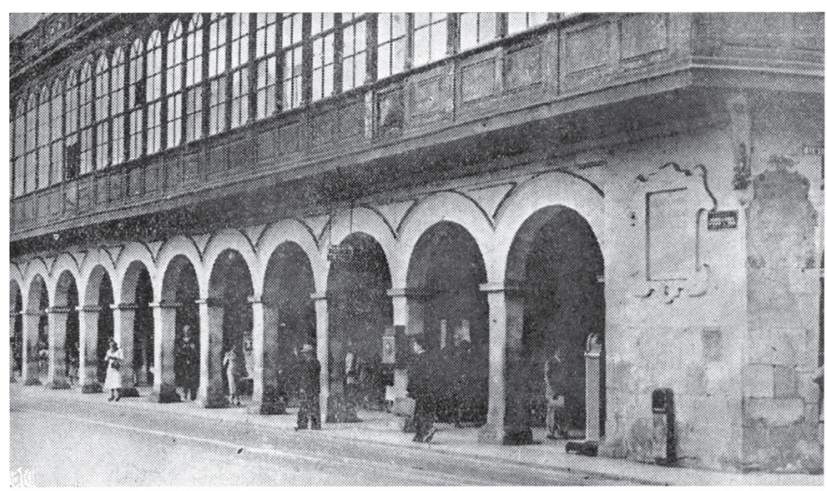

Portales de la Plaza de Armas de Lima. El viejo: piedra, sinceridad constructiva, arquitectura de su época.- El nuevo: concreto imitando piedra, ni concreto, ni piedra, falsedad constructiva, arquitectura anacrónica.

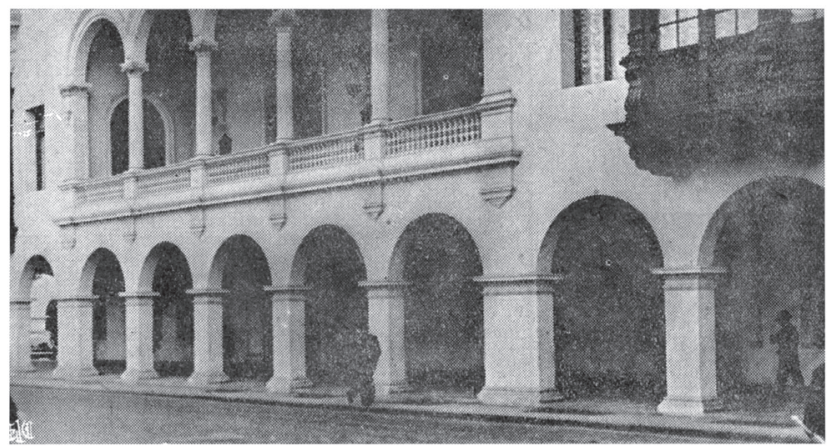

Figura 4. Portales de la Plaza de Armas antes y después de la reforma (Miró Quesada 1951).

${ }^{11}$ Los estudios de James Holston y Françoise Choay sobre modernización urbana y patrimonio arquitectónico, respectivamente, han sido referentes importantes para este ensayo. Ambos autores seńalan la influencia del ideario funcionalista durante los treinta (Holston 1989: 41 y ss.; Choay 2007: 10 y ss.). 


\section{MODERNIZACIÓN URBANA Y LA PLAZA A INICIOS DE SIGLO}

La reforma de los años cuarenta se dio en la estela de dos proyectos municipales previos, uno en 1901 y otro en 1906, para demoler y reformar los portales de la plaza de Armas. Ninguno de ellos fue acometido, pero dieron cuenta del interés oficial por modernizar dicho espacio. En efecto, por su centralidad simbólica y social, intervenir la plaza fue una constante preocupación de las autoridades desde el periodo colonial.

Desde temprano en el siglo XVII, siguiendo los lineamientos establecidos por las autoridades coloniales para las plazas mayores hispanoamericanas, la plaza de Lima alojaba en sus edificios circundantes a las principales instituciones coloniales: la catedral, el palacio arzobispal, los palacios de gobierno y municipal (localizado en el portal de Escribanos) y el portal de Botoneros. Esta organización aspiraba a establecer un espacio que, real o ficticiamente, sea el centro en torno al cual ordenar a la ciudad y sus habitantes. Tradicionalmente, la plaza no solo fue la principal sede de las ceremonias políticas y religiosas, sino también y sobre todo el más importante centro de intercambio social y comercial. Fue justamente por la presencia activa y permanente de mercaderes en el área que sus portales fueron apodados «de Escribanos» $\mathrm{y}$ «de Botoneros». ${ }^{12}$

Durante el periodo de reformismo borbónico, las intervenciones urbanas cobraron un tenor modernizador e ilustrado, expresado bajo ideales de ornato e higiene. En ese contexto, un proyecto para la plaza propuso «higienizarla» desalojando a los mercaderes informales que a diario la ocupaban. El proyecto no prosperó por la protesta de los comerciantes, situación que se repitió con otro muy similar planteado luego de la Independencia. ${ }^{13}$ No fue sino hasta la segunda mitad del siglo XIX que las autoridades lograron reubicarlos. Para ello fue necesaria la construcción del Mercado Principal (1852) y una reforma del centro de la plaza (1856). La propuesta del marmolista italiano Francisco Pietro-

${ }^{12}$ Cabe mencionar que el nombre original, «Plaza Mayor», fue cambiado en el XVIII por «Plaza de Armas». Recientemente, el primer nombre ha sido retomado. Para un estudio sobre la plaza durante el periodo colonial, véase Ramón 2012: 287 y ss., 299 y ss.

13 Ramón 1999: 61 y ss. 
santi para el centro de la plaza siguió los modelos del clasicismo en boga durante el periodo. El centro fue empedrado y se colocaron estatuas y jarrones de mármol. Un hecho sutil como la disposición de bancas para el descanso y la sociabilidad era coherente con el ideal de espacio público moderno, a la vez que limitaba el rango de acción de sus visitantes. La desordenada plaza pasó entonces a ser percibida como un espacio más regulado, pero también menos concurrido. ${ }^{14}$

A medida que la ciudad fue creciendo, las intervenciones oficiales en ella fueron en aumento. Superada la crisis económica traída por la Guerra del Pacífico, ${ }^{15}$ la administración de Nicolás de Piérola, en asociación con el sector privado, promovió la aparición de clubes y edificios para los sectores más acomodados al sur de la ciudad. En este contexto, escritores locales y extranjeros postularon los tópicos de la «Lima que se pierde» y la «haussmanización limeña». ${ }^{16}$ Este último término aludía a las intervenciones urbanas implementadas en París desde mediados del XIX para la apertura de grandes avenidas y bulevares, lo que supuso la demolición de la arquitectura tradicional.

En el marco de esta "haussmanización", la administración del alcalde Federico Elguera (1901-1908) buscó modernizar la plaza de Armas. En 1901, se dio inicio a una reforma del centro de la misma siguiendo el modelo pintoresquista del "parque inglés». ${ }^{17}$ La plaza recibió una nueva pavimentación en los caminos peatonales y la explanada fue convertida en área verde. Las bancas de mármol fueron reemplazadas por otras de metal, y las estatuas y los jarrones, removidos.

${ }^{14}$ Majluf 1994a: 23 y ss.

${ }^{15}$ En 1862, el presidente Ramón Castilla impulsó sin éxito la construcción de un nuevo palacio de gobierno. En 1872 el senador José Antonio García y García presentó un nuevo proyecto en otra locación. Dentro del debate suscitado se argumentó la necesidad de «nuevos centros». La crisis de la posguerra marcó el fin del proyecto (Callirgos 2007: 82-91). ${ }^{16}$ Este tópico fue aplicado también para otras ciudades latinoamericanas. Sobre el uso del término en la prensa limeńa entre 1850 y 1880, véase Ramón 1999: 104-105. En Lima fueron Luis Sadá y P. V. Jouanny quienes propusieron proyectos de este tipo; por otro lado, algunos viajeros franceses percibieron tal «haussmanización» (Ramón 1999: 105, 187 y ss.). 17 "Parques en la Plaza» 1901. Sobre el modelo del "parque inglés», véase Gorelik 2010: 60 y ss. 
Esta reforma fue parte de una serie de intervenciones de higienización y control social que el Estado y el Municipio implementaron en toda la ciudad. ${ }^{18}$ Dicha campaña tuvo una doble faz: por un lado, la construcción de modernas avenidas, edificios y espacios públicos; por otro, la destrucción de patrimonio arquitectónico colonial. Así, si bien ya desde mediados del XIX se había extendido una imagen negativa de los balcones de cajón, ${ }^{19}$ Elguera emprendió una campaña personal que los caracterizaba además como «inmorales» (por "propiciar la apatía») y demandaba un estilo más en armonía con la «higiene moderna». ${ }^{20} \mathrm{Su}$ empresa fue caracterizada como "modernista» y criticada por escritores tradicionalistas como Teófilo Castillo y José Gálvez. ${ }^{21}$

Las dos facetas de esta campaña se expresaron en la proyectada avenida 28 de Julio, pieza central de un sistema de vías en la estela del urbanismo haussmaniano planeada para unir la plaza de Armas con otra nueva que se construiría en la estación San Juan de Dios, hoy plaza San Martín. La construcción de esta avenida habría implicado la destrucción del portal de Botoneros, la ampliación del pasaje de Petateros (identificado desde hace tiempo como «foco infeccioso») al medio del mismo, y el levantamiento de un nuevo conjunto arquitectónico. ${ }^{22}$ Con esta obra, Lima tendría, según Elguera, «al fin una plaza del siglo XX y no ya del XVI». ${ }^{23}$ Si bien esta afirmación ignoraba la reforma de 1856, su proyecto sí dio inicio a una nueva idea acerca de cómo reformar la plaza: a partir de la destrucción de arquitectura tradicional y la construcción de avenidas y edificios «de última moda».

${ }^{18}$ Para un análisis de esta reforma, véase Muñoz 2001: 51 y ss. Sobre el higienismo de inicios del XX, Ramón 1999: 167 y ss.

${ }^{19}$ Desde fines del XVI se criticó la fragilidad de los balcones. Los ataques más intensos se dieron a mediados del siglo XIX, hasta llegar a prohibirse, sin éxito real, en 1872 (Harth-terré y Márquez Abanto 1959).

${ }^{20}$ Elguera 1903.

${ }^{21}$ Cabe indicar que la «nueva» arquitectura limeńa de inicios de siglo no tuvo un programa o una afirmación anti-tradicionalista similar a la del modernismo literario del mismo periodo, ni a la del modernismo funcionalista de la Agrupación Espacio. Sobre el tradicionalismo en arquitectura y arte, véase Villegas 2006: 47 y ss.

22 Percepciones negativas sobre el pasaje Petateros pueden rastrearse hasta mediados del siglo XVIII. Véase Ramón 1999: 184 y ss.

${ }^{23}$ Elguera 1901. 
El proyecto no fue acometido por desacuerdos con los propietarios de los predios. Ello no impidió que, en 1906, Elguera intentara de nuevo una reforma muy similar. El diseño (Fig. 5), publicado en la memoria de la Municipalidad y en la prensa, proponía dos edificios afrancesados de cuatro pisos, una vez más en reemplazo de los portales coloniales de Botoneros. En su defensa del proyecto, Elguera evocó las alteraciones urbanas llevadas a cabo en Buenos Aires, en la estela de las parisinas, a la vez que apeló a ideales modernos de ornato e higiene. ${ }^{24} \mathrm{El}$ nuevo proyecto fracasó también.

Al no contar con una ley de expropiación de previos privados, como la de Buenos Aires o París, ${ }^{25}$ el Municipio tuvo problemas para ejecutar sus ambiciosos proyectos de intervención urbana. El sector privado, en cambio, contó con mayor capacidad para renovar el paisaje urbano con elegantes edificios beaux arts. La fotografía urbana del periodo exaltó aquellos edificios de gran escala, con una retórica visual que los hacía sobresalir individualmente entre construcciones tradicionales de menores dimensiones.

Un caso ejemplar fue el edificio Oechsle (Fig. 6), diseñado por Claude Sahut en 1912 siguiendo modelos franceses, el cual destacaba con sus cuatro pisos entre las construcciones coloniales de dos niveles. Este tipo de intervención «individualista», que no tomaban en cuenta el estilo o el contexto circundante, fue común dentro del eclecticismo y el beaux arts del periodo. ${ }^{26}$ Lo insólito del edificio, sin embargo, fue su emplazamiento: este se encontraba en medio del portal de Botoneros de la plaza de Armas y, para su realización, fue necesario demoler una parte de su arcada colonial. ${ }^{27}$

${ }^{24}$ Elguera 1906: viii. Sobre París como referente para las modernizaciones en Lima, véase Muñoz 2001: 46.

${ }^{25}$ Conscientes de esta dificultad, las autoridades buscaron otros medios para monumentalizar la plaza. En 1914, el gobierno central propuso, sin éxito, que un monumento originalmente planteado para la plaza San Martín sea localizado en la de Armas (Mejía 2013). ${ }^{26}$ La gran escala fue puesta en boga por los edificios eclécticos de exposiciones universales, y empleada luego en arquitectura pública (Kidney 1987: 18). El eclecticismo trajo a colación el debate sobre si los edificios tenían que ser contextuales o podían ser autónomos (Port 1995: 198). En Europa, tanto el beaux arts como el eclecticismo citaron el pasado, pero el primero lo hizo de modo más riguroso y académico que el segundo. En Lima, la diferencia entre ambas tendencias fue difusa. Como el art nouveau, estas tendencias de inicios de siglo no han recibido aún estudios especializados en Perú.

27 Ballón Lavagna 1975: [76]. 

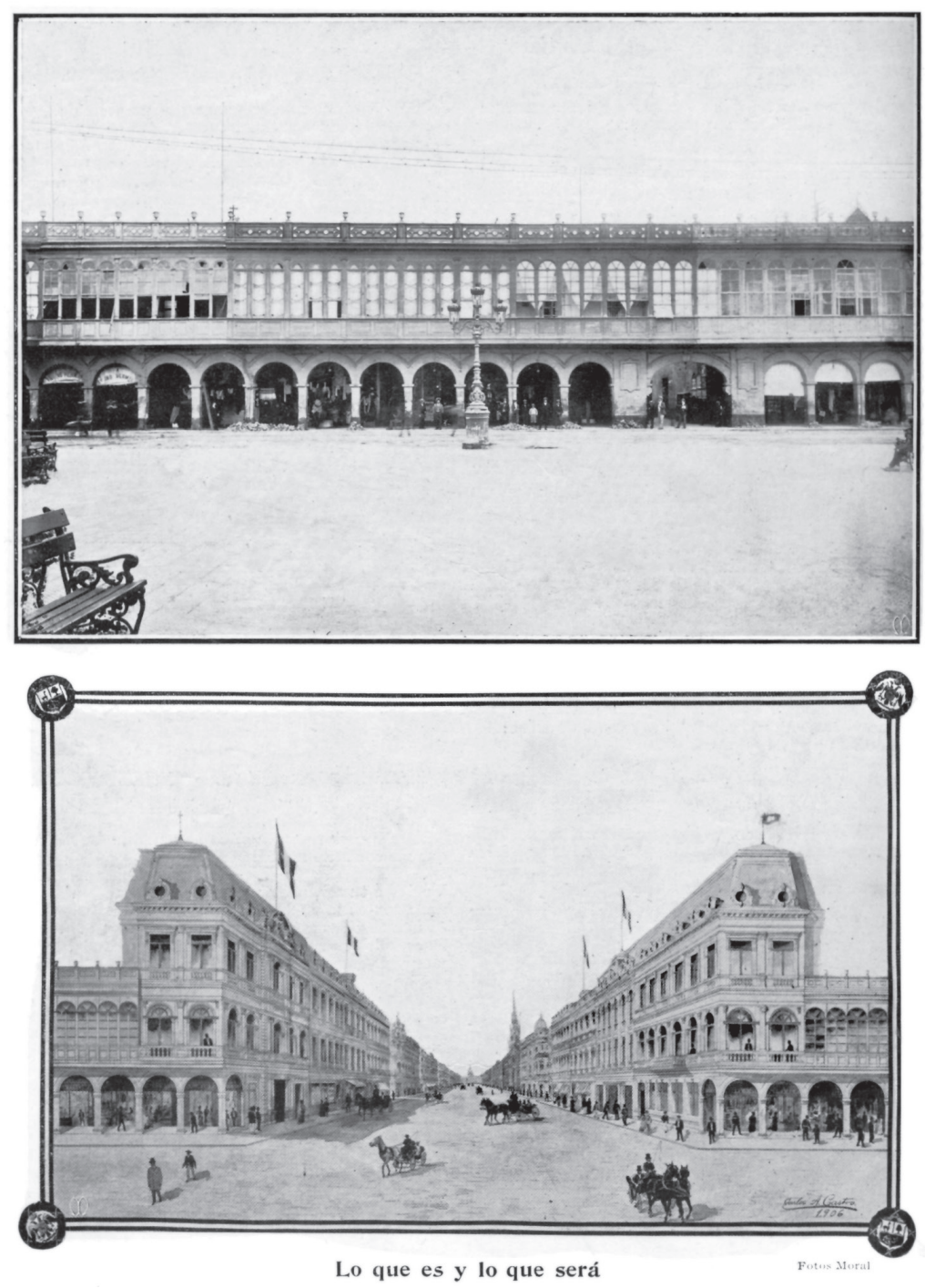

Figura 5. Carlos A. Castro, «Lo que es y lo que será [proyecto de la avenida 28 de Julio]» («Nueva Avenida»1906). 


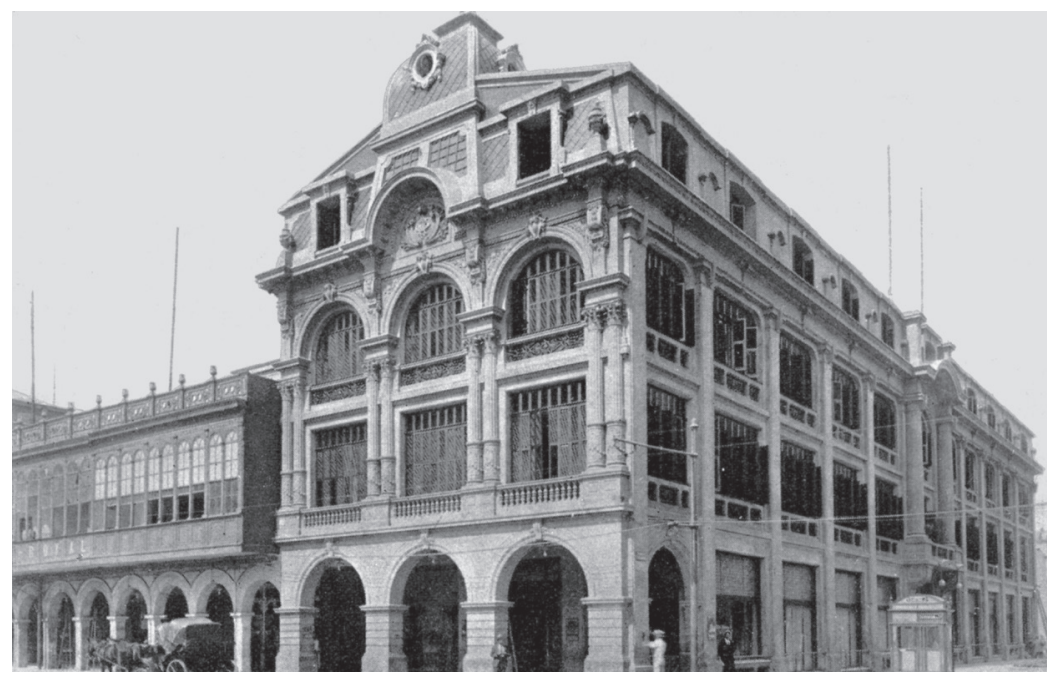

Figura 6. Sociedad F. Oechsle \& Co., ca. 1924 (Centurión Herrera 1924: 344).

El edificio Oechsle cumplió parcialmente el proyecto de la nunca realizada avenida 28 de Julio (Figs. 5-6). Su altura de cuatro niveles y su ubicación, junto al pasaje de portal de Botoneros, era idéntica a la proyectada para los edificios en torno a la avenida. Incluso la fachada era similar, tanto en el diseño afrancesado de su mansarda como en sus nuevos portales en el primer nivel. De esta manera, un intento oficial por intervenir la plaza de Armas tuvo como lejano eco un centro comercial. En última instancia, la empresa privada tuvo más poder que el Estado en la configuración del espacio público.

Para entonces, la plaza no era más el concurrido centro social y simbólico de épocas anteriores. Públicos diversos preferían espacios menos regulados. Los de mayores recursos formaron sus propios centros al sur de la ciudad. La famosa frase del escritor Abraham Valdelomar («El Perú es Lima, Lima es el Jirón de la Unión») fue enunciada en este contexto y refería en parte un irónico desencanto con respecto a la vida moderna burguesa y cierta nostalgia por un centro de la ciudad que fuera claro e identificable. ${ }^{28}$ 


\section{LA REFORMA NEOCOLONIAL DE HARTH-TERRÉ}

Los proyectos planteados por Emilio Harth-terré para la plaza entre las décadas de 1920 y 1930 siguieron el ideal de modernización urbana a partir de la destrucción de la arquitectura tradicional y el levantamiento de grandes y flamantes edificios, circundados a su vez por espaciosas avenidas. Aunque resulte paradójico, el arquitecto añadió a tal ideario un interés por devolver a la plaza un sentido de tradición que respondía al temor por la «Lima que se pierde». Desde su puesto en la Inspección de Ornato de la Municipalidad presentó su primer proyecto para dicho espacio (Fig. 7), en el que proponía demoler los portales coloniales de piedra y reemplazarlos por edificios neocoloniales de cuatro niveles. Cada nuevo edificio presentaría en su fachada una extensa portada desde la base hasta la punta, dos delgadas torres en la parte superior, dos enormes balcones de madera al medio y amplios arcos en la parte inferior. Los nuevos edificios, así como sus pasajes intermedios y avenidas aledañas, eran mucho más grandes que los originales, pero en líneas generales imitaban la estructura de los mismos.

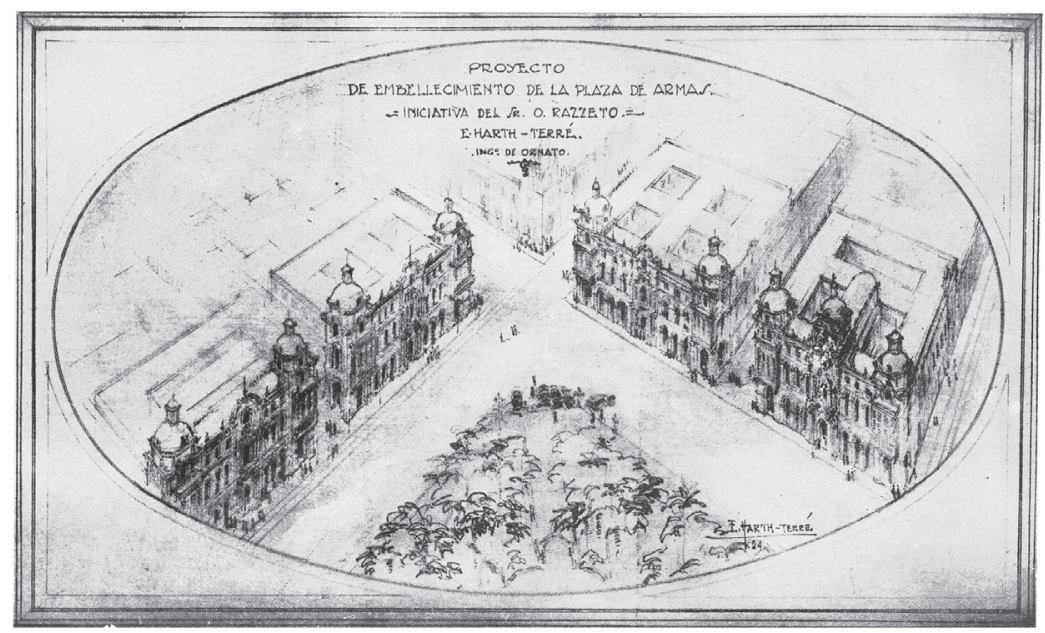

Boceto del proyecto del ingentero Mnnicipal, seĩor Harth Terrs, para in modernización de la Plasa de Armas

Figura 7. Proyecto de remodelación de la Plaza de Armas, por Emilio Harth-Terré («Por el embellecimiento" 1924). 
La ornamentación sería el aspecto más distintivo entre los nuevos edificios y sus antecesores. En lugar de discretos balcones republicanos corridos, cada edificio contaría con dos balcones de cajón tallados de escala mayor. Además, mientras que los portales originales carecían de mayor ornamentación, los de Harth-terré tendrían molduras y torres profusamente decoradas. Donde el incremento ornamental se hizo aún más patente fue en las recargadas portadas de los edificios, que citaban las de las iglesias barrocas andinas. Tal exaltación de elementos coloniales en flamantes edificaciones oficiales llama la atención si se recuerda que pocas décadas antes el alcalde Elguera había arremetido contra la arquitectura colonial. ${ }^{29}$

La revaloración de esta arquitectura venía desarrollándose desde años atrás. Por un lado, la arquitectura pintoresquista de la década de 1910, usada para las casas de la clase alta en localidades anexas a Lima, incluyó citas coloniales. ${ }^{30}$ Por otro lado, ciertos intelectuales argentinos y mexicanos se afiliaron a la teoría del «estilo nacional», inspirada en los estudios formalistas del suizo Heinrich Wölfflin, y la asociaron a las formas de la arquitectura colonial. ${ }^{31}$ Este debate teórico estuvo focalizado en Buenos Aires, pero tuvo un eco importante en Lima. En este contexto, Harth-terré diseñó «modernas» residencias con recargadas fachadas neobarrocas pero con amplios e iluminados espacios interiores, así como edificios neocoloniales enmarcados en anchas avenidas aledañas. En un ensayo posterior, de clara filiación wölfflianiana, este afirmó que lejos de ser una «resurrección

${ }^{29}$ En 1924, Elguera promovió un diseño del arquitecto Enrique Bianchi, «adaptado» del Palacio de Justicia, que seguía una línea compositiva academicista y que sería erigido en la flamante plaza San Martín (Elguera 1924). Otro proyecto de Harth-terré del mismo año exploró también la posibilidad de que la Municipalidad ya no estuviera en la plaza, convirtiendo el predio original en un parque («Parque Ayacucho»1924).

${ }^{30}$ Un caso pionero de neocolonial limeño fue la casa de campo diseñada en 1911 por Rafael Marquina en Chosica, que sería comentada y dibujada por Teófilo Castillo, temprano promotor del nacionalismo en las artes (Castillo 1912).

${ }^{31}$ Sobre las relaciones entre nacionalismo e historia del arte en el contexto intelectual de Wölfflin, véase Passini 2013: 131-141. 
arqueológica», el neocolonial era poner en las «líneas firmes y sencillas de la arquitectura de hoy, la esencia del arte que produjimos hasta ayer». ${ }^{32}$ Hacia la década de 1920, las artes oficiales en Lima habían cobrado un tono nacionalista auspiciado por el gobierno de Augusto B. Leguía (1919-1930) y expresado tanto en el indigenismo como en el hispanismo. En 1924, mientras que el pintor José Sabogal poblaba de tapadas limeñas el Salón Ayacucho del palacio de gobierno, el arquitecto Ricardo Malachowski concluyó su palacio arzobispal en estilo neocolonial; ${ }^{33}$ ambos edificios estaban situados en la plaza de Armas. Si bien la historiografía del arte ha enfatizado una dicotomía entre indigenismo e hispanismo (siendo el primero más "progresista» y el segundo «aristocrático»), cabe recordar que ambas tendencias compartieron productores y mecenas. La mayor diferencia residió en que los indigenistas supieron dotar de un tono modernista a sus pinturas, al enfatizar la "diferencia» de sus personajes andinos, y por sus técnicas antiacadémicas consideradas afines al carácter «fuerte» de lo indígena. ${ }^{34} \mathrm{El}$ neocolonial limeño, en cambio, se mantuvo en la estela academicista del beaux arts en su diseño de estructuras y espacios.

La casa colonial de Torre Tagle fue una imagen emblemática de este horizonte nacionalista criollo. En ese sentido, no solo fue conservada del desgaste y de eventuales intervenciones - a diferencia de casos menos prestigiosos como los portales de Escribanos y Botoneros-, sino que además fue utilizada como modelo para la arquitectura moderna. ${ }^{35}$

${ }^{32}$ Harth-terré 1947a: 25, 5.

${ }^{33}$ El palacio original fue demolido en 1898 . Sobre sus reformas, véanse «Nuevo palacio arzobispal proyecto» 1909; «El nuevo palacio arzobispal» 1911; «El Palacio Arzobispal» 1924.

${ }^{34}$ Majluf 1994b: 618-619. Para un estado de la cuestión sobre indigenismo y criollismo en el arte y la cultura visual de la primera mitad del XX, véase Majluf y Wuffarden 2013. ${ }^{35}$ Resulta difícil identificar un canon de arquitectura colonial en un periodo de exigua producción historiográfica. Véase el repaso historiográfico en San Cristóbal 1999. Es indudable, sin embargo, que la casa Torre Tagle tuvo una importante presencia en el imaginario intelectual y artístico de inicios del siglo XX. Véase «La regia mansión» 1921. Torre Tagle fue una imagen recurrente en las pinturas idealizadas del pasado colonial de Teófilo Castillo a inicios de siglo (Villegas 2006: 84, 111). 
Tanto Malachowski como Harth-terré citaron su portada barroca y sus recargados balcones de madera tallada en sus respectivas propuestas para el nuevo palacio arzobispal y los nuevos portales de la plaza. ${ }^{36} \mathrm{El}$ diseño de Malachowski fue descrito por Abraham Valdelomar como poseedor de un "estilo propio", característico de Lima. ${ }^{37}$

Este horizonte estético, sin embargo, no fue lo que motivó el proyecto de Harth-terré. Un incendio en el palacio municipal (1923), ${ }^{38}$ emplazado en el portal de Escribanos, fue lo que llevó al arquitecto a proponer no solo la reforma del palacio, sino de toda la plaza. Para entonces, esta empezaba a ser percibida como un espacio fallido. Tal percepción se debió en parte, como comentó un escritor, al "paquidermo muerto" que era el edificio Oechsle; ${ }^{39}$ pero fue enfatizada por la construcción de la plaza San Martín. Esta última se enmarcó en el ambicioso programa de reformas urbanas de Leguía y fue estimada como un «golpe de gran ciudad» que hacía lucir «remota» a la plaza de Armas, «como si en lugar de ser real fuera un grabado antiguo propicio a la exhumación». ${ }^{40}$ Diseñada por el escultor español Manuel Piqueras Cotolí en 1920, la plaza San Martín ordenaba axialmente, en torno al monumento central del libertador, sus edificios neocoloniales y sus amplias calles y avenidas para el tránsito peatonal y vehicular (Fig. 9). ${ }^{41}$

El Municipio reconoció la urgencia de reformar el palacio incendiado, ${ }^{42}$ pero tal intención no se concretó en obras. Desde entonces, Hath-terré promovió la necesidad de una reforma «por escrito en los periódicos,

${ }^{36}$ Harth-terré y Márquez Abanto 1959: 44.

37 Valdelomar 1916.

38 «El voraz incendio» 1923.

39 "Por el embellecimiento» 1924.

40 «La Plaza San Martín» 1930: 9. Leguía llevó a cabo las reformas que intentaron sin éxito las administraciones de Nicolás de Piérola y Federico Elguera, con quienes estuvo vinculado (Ludeńa 2009: 146); además, firmó un contrato con The Foundation Company, donde se estipulaba ensanchar las avenidas, pavimentar y renovar en concreto las calles, plazas, monumentos y paseos de la capital. Al término del Oncenio, Lima se encontraba pavimentada casi al noventa por ciento (Callirgos 2007: 285-297).

41 Sobre la plaza, véase Ludeńa 2004: 54, 66. Sobre el monumento, Mejía 2013.

${ }^{42}$ El Concejo Municipal decidió el 6 de noviembre de 1923 reconstruir el palacio municipal en su antiguo solar. Véase Riva-Agüero 1934. 
en libros y conferencias, en julio de 1924, en mayo de 1926, en abril de 1927, en 1929, 30 y $31 » .{ }^{43}$ Durante dicho periodo, su prestigio fue en aumento, al asumir el diseño de diversos espacios públicos y residenciales en el marco del crecimiento urbano limeño de los treinta. No obstante, Harth-terré siguió su campaña por la reforma de la plaza de Armas, por la que también abogaron figuras tan influyentes como el intelectual José de la Riva-Agüero y José Sabogal. ${ }^{44} \mathrm{El}$ interés compartido por estos tres intelectuales, en otros aspectos tan disímiles, da cuenta de la centralidad simbólica atribuida a dicho espacio público por parte de su generación.

La reforma, sin embargo, tuvo que esperar más de una década. En 1938, una vez más un edificio, y no un guion urbano, puso en movimiento a las autoridades. El nuevo palacio de gobierno, con su extenso retiro, estaba por ser concluido, y su actual dimensión hacía necesario un ensanchamiento de las calles aledańas. Tan rotunda alteración de la paisajística tradicional de la plaza no fue criticada en la prensa, sino que fue aprovechada para que el Municipio abriera un concurso de «alineamiento de los portales». ${ }^{45} \mathrm{Si}$ bien las bases del certamen no establecían la destrucción de los mismos, la sugerían. En realidad, desde 1937 se habían llevado a cabo estudios que concluían en la necesidad de que los portales se rehagan en un estilo "más afín» a los nuevos palacios de gobierno y arzobispal, y que proponían extender la calzada para el estacionamiento y tránsito vehicular. El entonces alcalde Eduardo Dibós Dammert caracterizó ambas reformas como «muy urgentes». ${ }^{46}$

\footnotetext{
${ }^{43}$ Véase la carta dirigida a José de la Riva Agüero y Osma, Lima, 12 de noviembre de 1934, en The Latin American Library, Universidad de Tulane, Harth-terré Collection, Manuscritos, Caja 1, Folder 1.

${ }^{44}$ En 1938, el Municipio reunió opiniones de diversos arquitectos e intelectuales con respecto a dónde situar el nuevo palacio municipal. Uno de ellos, Rafael Marquina, señaló que la plaza no era más «el centro» de la ciudad, mientras que Sabogal, Harth-terré y Riva-Agüero apostaron por que el palacio continúe en su tradicional emplazamiento («La reconstrucción del Palacio Municipal»1938: 34-36).

45 «Documentos municipales» 1938.

46 Sobre los estudios de 1937, véase «Memoria presentada al Concejo» 1938. Para las declaraciones del alcalde, véase «Embellecimiento de la Plaza de Armas» 1938.
} 
Ese año, Harth-terré y el arquitecto José Álvarez Calderón presentaron una propuesta que seguía el perfil y la escala del proyecto presentado por Harth-terré en 1924. ${ }^{47}$ La mayor alteración fue una ornamentación más depurada en molduras y balcones, siguiendo el gusto en edificios oficiales de la época por formas cercanas al art déco. ${ }^{48}$ La propuesta tuvo una presencia gravitante entre autoridades y arquitectos, ${ }^{49}$ pero no se plasmó en obras.

No fue sino hasta 1939 que el Poder Ejecutivo decretó una ley para que se concrete la reforma a partir de un concurso público. El dictamen establecía el rediseño de las fachadas de los inmuebles fronterizos a la plaza y obligaba a los propietarios a reconstruir sus propiedades siguiendo el proyecto ganador en el "plazo improrrogable de dos años». ${ }^{50}$ Seis meses después, en setiembre de 1939, la revista más importante del gremio, $E l$ Arquitecto Peruano, publicó los finalistas del concurso. ${ }^{51}$

El segundo puesto fue ocupado por Carlos Morales Machiavello y Eugenio Montagne van de Vorde (Fig. 8). Su diseño se destacaba entre todos por mantener los portales coloniales, proponiendo para ello un segundo nivel retirado con terrazas. ${ }^{52}$ En las terrazas se reproducirían

47 «Alineamiento de la Plaza de Armas» 1938.

${ }^{48}$ Para una reflexión sobre el neocolonial y el art déco, a favor del segundo, véase «La Lima que veo venir» 1924. Sobre la relación entre art déco y edificios públicos, «La tendencia moderna» 1939. En Progresos del Perú (1945), documento de propaganda del gobierno de Óscar Benavides, se ofrece un catálogo de edificios militares y comedores populares en la estela del art déco. Es posible ver un diseño art déco indigenista de Harth-terré en «Adaptación del arte» 1940.

49 «La reconstrucción del Palacio Municipal»1938; «Exposición de las labores realizadas» 1938.

50 «Plazo para la reconstrucción» 1939.

51 «Concurso para la reconstrucción» 1939. La comisión calificadora estuvo integrada por el director general de Fomento Luis F. Díaz, el inspector de obras del Concejo Alberto Jochamowitz, Rafael Marquina, Augusto Benavides Canseco y Carlos Montero Bernales. 52 Dado que no quedaba claro si debían o no respetarse los portales coloniales, Silva Santisteban, uno de los participantes, refirió tiempo después «la absoluta falta de experiencia que había entonces sobre concursos dio lugar a la elaboración de unas bases elementales que en vez de ayudar crearon dificultades insalvables respecto a los límites de propiedad, aires, servidumbres, etc. Finalmente las bases se abandonaron y cada concursante procedió de acuerdo a su propio criterio» (citado en Abad y Cárdenas 1975: 65). Al plantear su propuesta, Morales y Montagne fueron conscientes del valor histórico de los portales (Tarazona 1971: 30). 

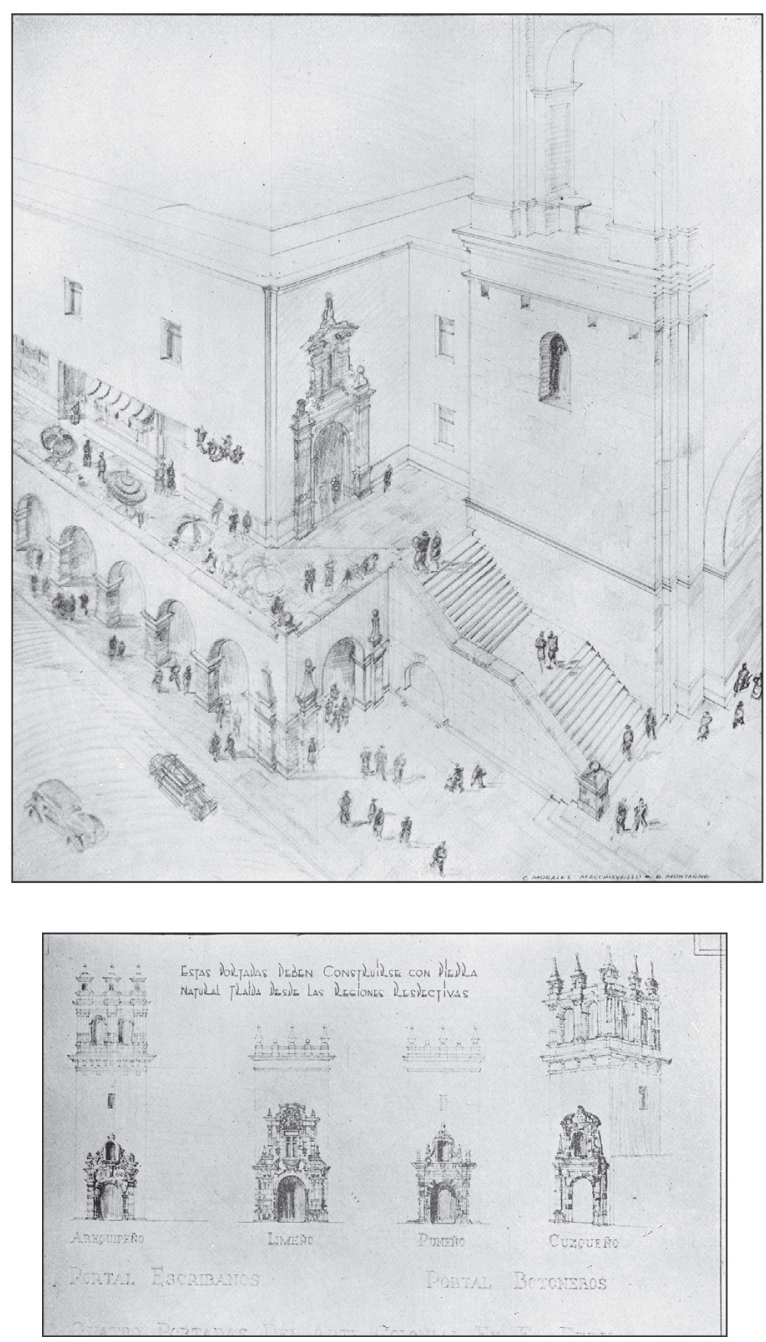

Figura 8. Proyecto presentado por los ingenieros C. Morales M. y E. Montagne («Concurso para la reconstrucción» 1939: [52]). 
"cuatro portadas del arte colonial en el Perú», cada una siguiendo un «estilo regional» (arequipeño, limeño, puneño y cuzqueño) y construidas con piedras traídas de dichas localidades. Esta propuesta reflejaba el tono regionalista que en contextos como el argentino tuvo el neocolonial desde sus inicios. ${ }^{53}$ En el Perú, la investigación y la difusión de arquitectura regional se encontraba más desarrollada que en los veinte. Guarda sentido entonces que los arquitectos hayan ofrecido un repertorio regionalista, aunque no por ello menos selectivo de casos puntuales y prestigiosos, de la arquitectura virreinal. ${ }^{54}$

La propuesta ganadora, como era de esperarse, fue la de Harth-terré y Álvarez Calderón, en mucho similar a la de 1938. El rasgo más característico de la propuesta, de ornamentación más depurada que las versiones anteriores, fue la enorme dimensión de sus balcones. Refiriéndose a este diseño, Harth-terré comentó tiempo después que sus balcones se inspiraron en los del siglo XVIII, pero se amoldaban a «las necesidades de un edificio moderno». Así, demostraban que lo colonial podía "convenir sin obstáculo y congruentemente» a un moderno edificio público. ${ }^{55}$

La comisión evaluadora — por sugerencia de Rafael Marquina, entonces presidente del Concejo Nacional de Conservación de Monumentos Históricos y Artístico — decidió que para el portal de Escribanos se siga el diseño ganador y, para Botoneros el segundo puesto, conservando así un portal colonial. ${ }^{56}$ Ello tenía sentido pues solo el portal de Escribanos

${ }^{53}$ De manera análoga, Harth-terré diseñó en 1928 hoteles inspirados en tipologías regionales («Modelo Lima» 1928; «No. 3 Modelo» 1928; "No. 5 Modelo» 1928).

${ }^{54}$ El libro Arquitectura peruana de Héctor Velarde, primera panorámica sobre el tema, ofrece una noción de qué edificios conformaron el canon de arquitectura colonial en el periodo (Velarde 1946: 61-174). Se mencionan ahí edificios oficiales e iglesias como la catedral y la iglesia Santo Domingo en Lima, la catedral en Cuzco, la iglesia de la Compañía en Arequipa, así como residencias de familias acaudaladas como la casa Torre Tagle. ${ }^{55}$ Esta cita proviene de un informe presentado por Harth-terré y Álvarez Calderón, elevado al presidente de la comisión del concurso en 1939 (Harth-terré y Márquez Abanto 1959: 45). Para el diseño de Harth-terré y Álvarez Calderón, véase «Concurso para la reconstrucción» 1939: [49].

${ }^{56}$ Harth-terré 1971: 24; Tarazona 1971: 30. Para un boceto de ambas propuestas combinadas, véase «Proyecto para la reconstrucción» 1940. 
había quedado dañado por el incendio y, por alojar una sede administrativa, este era el que requería una reforma urgente.

El palacio municipal fue el primero en ser construido. Las obras, sin embargo, no empezaron hasta $1941 \mathrm{y}$, por dificultades para expropiar los predios, su estructura no estuvo terminada hasta $1943 .{ }^{57}$ Ese mismo año empezaron las obras en el otro edificio de Escribanos: el Club de la Unión. Empero, contra lo estipulado por Harth-terré y Álvarez Calderón, la fachada del club imitó a la del palacio municipal. El 28 de julio de 1944, el nuevo palacio municipal estuvo terminado y el hecho fue promocionado en los medios y fue portada en agosto de $E l$ Arquitecto Peruano.

Las obras en Botoneros, en cambio, no empezaron hasta 1947 y no recibieron mayor cobertura de la prensa. Para dicho portal, el veredicto del jurado había sido que se siguiera el diseño del segundo puesto. Sin embargo, cuando el Municipio inició las obras, el diseño que siguió fue una imitación de la fachada y estructura del palacio municipal. ${ }^{58}$ No se han encontrado fuentes para explicar el cambio de decisión. Es posible argüir que el diseño de Morales y Montagne era más costoso de implementar, por implicar el levantamiento de terrazas y el mantenimiento de portales de piedra. El factor económico debió ser uno de peso en un proceso que enfrentó demoras y polémicas, como se evidencia por los numerosos reclamos de propietarios particulares por problemas de

${ }^{57}$ La construcción no estuvo exenta de polémica. En 1939, el concejal Ramírez Clavero se apoyó en «un sentir de la ciudad» para exigir un nuevo espacio para el palacio, argumentando que el predio tradicional no daría por satisfechas las necesidades de una ciudad moderna («Sesión ordinaria del sábado» 1940). Sobre las obras y sus demoras, véase Archivo Histórico Municipal de Lima, Obras Públicas, Expediente Letra O, número 2408, folio 401, serie 1, año 1941, segundo semestre.

${ }^{58}$ En 1947, Rafael Marquina dirigió una carta al Concejo Municipal y a la Sociedad de Arquitectos oponiéndose a la demolición del portal de Botoneros. Su campaña fue apoyada por Morales Machiavello y Luis Miró Quesada Garland (Tarazona 1971). El propio Harth-terré criticó que su diseño para el palacio municipal sea imitado en el Club de la Unión y los dos edificios del portal de Botoneros (Carta a Marcos Landman, Lima, 14 de setiembre de 1968, en The Latin American Library, Universidad de Tulane, Harth-terré Collection, Manuscritos, Caja 1, Folder 1). 
expropiación y de los comerciantes formales e informales que iban a perder sus lugares de trabajo. ${ }^{59}$

El 11 de enero de 1952, los comerciantes informales seguían sin desocupar el portal. El 15 de abril solicitaron formalmente al Concejo extender su permanencia, argumentando que aún no se iniciaban las obras de reconstrucción en ningún sector de los portales. Su reclamo fue denegado y para el 20 de agosto el pasaje estaba desalojado. ${ }^{60}$ Ese mismo año terminó la demolición y el Consejo Nacional de Conservación y Restauración de Monumentos Históricos solicitó al Concejo Municipal enviar las piedras del portal a la Escuela de Bellas Artes. ${ }^{61}$

Para entonces, los espacios urbanos de la ciudad habían aumentado exponencialmente. Si en 1940 la capital sobrepasaba los 645 mil habitantes, en 1950 superó el millón, en buena medida debido a los procesos migratorios desde otras ciudades del país. ${ }^{62}$ Con el crecimiento demográfico vinieron problemas de vivienda y, ante la desidia estatal, migrantes y limeños de menores recursos optaron por construir «barriadas» fuera de la ciudad. ${ }^{63}$ Si cuando fue proyectada por primera vez la reforma neocolonial de la plaza buscó devolver centralidad simbólica a un espacio

${ }^{59}$ Las demoras en el proceso produjeron variaciones y cambios de ley, que no hicieron sino dilatarlo más. La construcción de ambos portales había sido establecida por ley n. ${ }^{\circ} 8854$ de 1939. Sin embargo, no fue sino hasta el 2 de octubre de 1943 que por resolución suprema n. ${ }^{\circ} 921$ se aprobó el proyecto para el portal de Botoneros. El proceso no continuó hasta 1944 , cuando por resolución suprema n. ${ }^{\circ} 2$ del 7 de enero y por la ley n. 9125 se obligó de manera improrrogable la expropiación de las fincas (Archivo Histórico Municipal de Lima, Obras Públicas, Expediente Letra C, número 279, folio 47, serie 1, año 1943, segundo semestre; Expediente Letra O, N. ${ }^{\circ}$ 2434, folio 406. Serie 1 , año 1945 , primer semestre).

${ }^{60}$ Archivo Histórico Municipal de Lima, Obras Públicas, Expediente Letra C, N. ${ }^{\circ} 923$, folio 155. Serie 2, año 1952, primer semestre.

${ }^{61}$ Archivo Histórico Municipal de Lima, Obras Públicas, Expediente Letra C, N. ${ }^{\circ} 4444$, folio 74. Serie 1, año 1952, primer semestre. Una crónica de 1997 reveló el estado de abandono de las piedras en un almacén municipal, sugiriendo que estas nunca llegaron a Bellas Artes (Vallejos 1997: 44).

${ }^{62}$ Contreras y Cueto 2010: 276, 302.

${ }^{63}$ En 1955 se fundó Ciudad de Dios, que marcó la pauta de otras barriadas al articularse a la ciudad «oficial» y llegar a constituir un eje urbano al sur (Sandoval 2014: 105 y ss.). 
que empezaba a ser relegado, en 1950 ya ninguna reforma de edificios habría podido colmar tal intención.

En 1954, el escritor Eduardo Carrera lamentaba la demolición de los portales tradicionales de la plaza, "para dar cabida al automovilismo que [la] han convertido ya en estación o playa». En efecto, dotar a la plaza de anchas avenidas para automóviles como en la plaza San Martín (Figs. 9-10) había sido una de las intenciones de los diseños de reforma desde los veinte (Fig. 7). Como Carrera sugería, sin embargo, tal ímpetu modernizador no había sino restado interés social a la plaza. Esta parecía reducida a estacionamiento, o una mera referencia para turistas. ${ }^{64}$

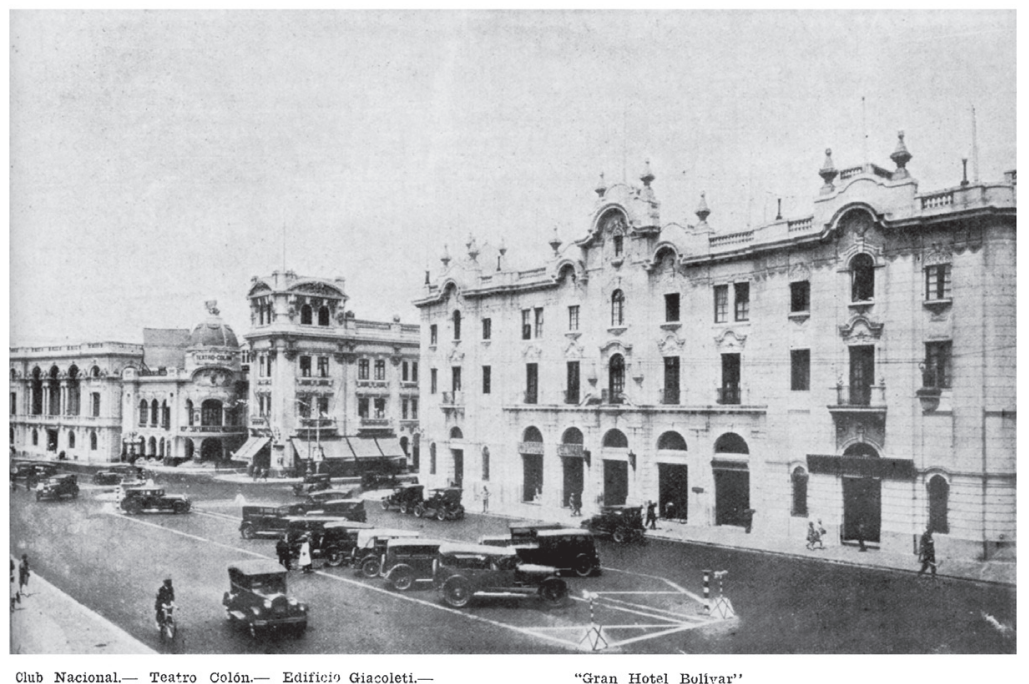

Figura 9. «El costado más amplio de la plaza San Martín y punto por donde se agita intenso tráfico automovilístico» («La Plaza San Martín» 1930: 7).

${ }^{64}$ Sobre la plaza como estacionamiento, véase Carrera 1954, 177. En sus «Notas sobre conservación», Harth-terré apunta: «El "AMBIENTE”. ¿Qué es “ambiente urbano"? I Formas, perfiles, plástica. / Un ambiente auténtico. / para el romántico, el historiador, el vagante y / añado: el Turista»" (The Latin American Library, Universidad de Tulane, Harth-terré Collection, Manuscritos, caja 1, folder 5). 


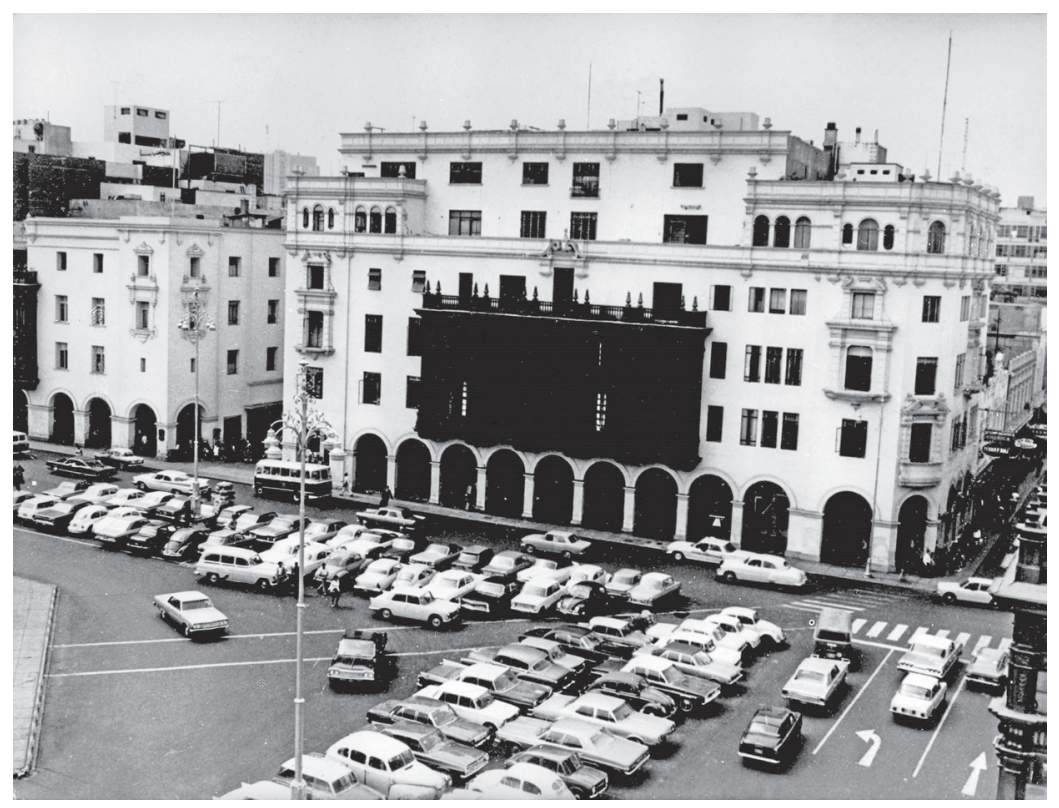

Figura 10. Pasaje Callao en la plaza de Armas en la década de 1950, Archivo Histórico Municipal, Municipalidad de Lima Metropolitana.

\section{LA AGRUPACIÓN ESPACIO Y EL «JAQUE MATE» A LA PLAZA}

En 1947, Luis Dórich, director de la Oficina Nacional de Planeamiento y Urbanismo, desarrolló un "plan piloto» para ordenar la expansión urbana en Lima a solicitud del gobierno central. ${ }^{65}$ El plan, diseñado con los urbanistas de filiación funcionalista Josep Lluís Sert, Paul Lester Wiener y Ernesto Nathan Rogers, fue publicado en 1949. Ahí se incluía una maqueta del área de la plaza de Armas (Fig. 11), aún no definitiva sino referencial para un estudio de costos. Lo más llamativo de la maqueta fue el carácter tangencial que se le daba a la propia plaza. Los edificios funcionalistas que la rodeaban eran los verdaderos protagonistas y aquella un mero telón de fondo.

${ }^{65}$ Sobre el plan, véase Kahatt 2015: 120-130. 


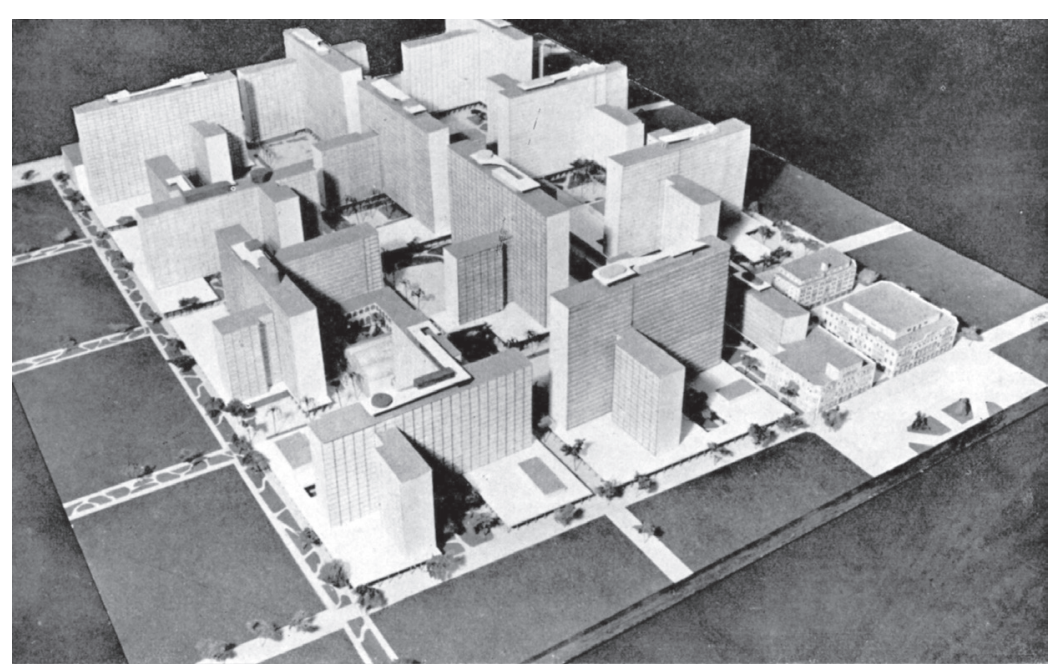

Figura 11. El Sector Central (Oficina Nacional de Planeamiento y Urbanismo 1949: 28).

Dentro del plan piloto, un nuevo "centro cívico», sin connotaciones religiosas o coloniales, sería construido al sur de la ciudad, a la vez que las nuevas zonas residenciales y unidades vecinales recibirían sus propios espacios públicos. Contra el ideal urbanístico de una ciudad con un solo núcleo ordenado por grandes avenidas, el plan articulaba la ciudad como una red de distintos ejes. El «sector central» ya no sería el centro social de la ciudad, sino uno "comercial y financiero».

En este contexto, el diseńo geométrico y la escala de los edificios que rodeaban a la plaza en el plan piloto cobraban sentido. Sin decoraciones historicistas, aunque no sin cierta teatralidad, estos cumplirían la función de alojar oficinas y beneficiar "la inversión del capital». ${ }^{66}$ Además, el «sector central» incluiría espacios abiertos para estacionamientos, áreas verdes y ciertas plazas tradicionales. A diferencia de lo que ocurrió con planes piloto de otras capitales, el de Lima tendría una «reglamentación especial» que prohibiría la demolición de «edificios de interés arquitectónico». La misma reglamentación prohibía la construcción de nuevos edificios «en estilo "colonial”». Estos últimos eran descritos como copias

${ }^{66}$ Oficina Nacional de Planeamiento y Urbanismo 1949: 28. 
«anacrónicas» que opacaban a sus modelos coloniales y generaban «incertidumbre».

En la versión original del plan, Sert propuso una «nueva tipología» para el centro, basada en el «contraste de alturas» de edificios nuevos con los históricos e historicistas. ${ }^{67}$ En la versión publicada, en cambio, si bien se mantenían ciertos edificios que habría sido polémico destruir — como la iglesia San Agustín o los flamantes portales neocoloniales de la plaza de Armas-, se reemplazaba buena parte de la arquitectura historicista de la zona por edificios funcionalistas. $\mathrm{El}$ "desconcertante» paisaje urbano que resultaba de ello fue notado por sus propios promotores. ${ }^{68} \mathrm{Como}$ proyectos previos de modernización urbana, el plan piloto propuso la demolición de la arquitectura del pasado y la construcción de edificios monumentales de diseño novedoso. En este caso, los edificios beaux arts y neocoloniales serían la arquitectura «anacrónica» que debía ser demolida.

Si bien los portales neocoloniales de la plaza serían conservados, el nuevo paisajismo de la zona los minimizaba, al rodearlos de bloques de gran escala. En su conjunto, la plaza terminaba siendo análoga a un "pozo de luz» para los edificios circundantes. Esta nueva concepción del que alguna vez fuera el espacio público más importante del país fue opuesta a la promovida por Harth-terré, Sabogal y Riva-Agüero pocos años atrás, pero fue compartida por un nuevo conjunto de arquitectos quienes, como Dórich, formaron parte de la Agrupación Espacio.

Antes de su publicación, Espacio abogó por el plan piloto desde sus columnas en El Comercio, y lo siguió haciendo después en la revista Espacio. ${ }^{69}$ En efecto, el plan cristalizaba muchas de las ideas de la agrupación sobre Lima y la plaza. Los términos "fachadista», "pastel

${ }^{67}$ La propuesta de Sert y Wiener para el centro cívico no fue publicada en el informe de la Oficina Nacional de Planeamiento y Urbanismo y quedaría inédita hasta 1953 (Kahatt 2015: 126-127).

68 «Lima adquirirá así un aspecto insospechado, desconcertante, para los que piensan que el urbanismo ideal consiste en la uniformidad de edificios y perspectivas haussmanianas, pero beneficioso para la salud de nuestro pueblo» («La hoja del urbanismo»1949). Este plan debe ser leído en relación con el Plan Voisin de Le Corbusier, el cual destruía los edificios del «viejo París», dejando apenas media docena de monumentos en pie.

${ }^{69}$ Miró Quesada 1948b; Sert y Wiener 1948; Bianco 1950. 
de bodas» $\mathrm{y}$ " jarterrorismo» fueron repetidos por sus miembros en este contexto para caricaturizar los edificios y reformas beaux arts y neocoloniales de la ciudad. ${ }^{70}$ Estos alegatos implicaban un juicio de valor, que situaba a Espacio por encima de sus antecesores.

Desde el momento de su concepción, Espacio atacó a las dos corrientes artísticas que, aunque cuestionadas, seguían siendo las de mayor aceptación: la pintura indigenista y la arquitectura neocolonial. En su reemplazo proponía la pintura abstracta y la arquitectura funcionalista, tendencias que pese a contar con prestigio internacional, contaban aún con escasa presencia en el medio local. ${ }^{71}$ El persistente protagonismo del neocolonial en Lima fue notado en 1943 por el arquitecto mexicano Manuel Chacón, quien publicó en la revista Arquitectura de dicho país una nota sobre el diseño del palacio municipal de Lima. ${ }^{72}$

No fue sino hasta 1944 que el arquitecto arequipeño Mario Gilardi dio una charla sobre Le Corbusier y la enseñanza de arquitectura en Santiago de Chile, donde estudió, para los estudiantes de la reciente Sección de Arquitectura de la Escuela Nacional de Ingeniería. Luego, en 1945, Luis Miró Quesada publicó su fundacional Espacio en el tiempo, libro que llamó la atención de la nueva generación de arquitectos. Adolfo Córdova y Carlos Williams, aún estudiantes, se acercaron a Miró Quesada con la idea de crear una revista, pero este sugirió que más urgente para el medio era la conformación de una agrupación con un programa estético común. ${ }^{73}$

De tal iniciativa surgió la "Expresión de principios» de Espacio. ${ }^{74}$ Según esta, el arte peruano del siglo XX solo había generado cambios

\footnotetext{
${ }^{70}$ Neira 1949.

${ }^{71}$ Sobre la inserción de la pintura abstracta en Lima, tomando el caso de su mayor protagonista, Fernando de Szyszlo, véanse Wuffarden 2011: 30 y ss.; y Kusunoki 2011. ${ }^{72}$ La línea editorial de la revista Arquitectura buscó definir en sus páginas una idea de la «arquitectura latinoamericana contemporánea». Mientras que en otros países esta noción fue representada principalmente por edificaciones funcionalistas, el único caso peruano comentado fue el aún «en vías de terminación» palacio municipal neocolonial (Flaherty 2013: 253-255).

73 Sobre la influencia de Gilardi y Miró Quesada entre los estudiantes de la Escuela de Ingenieros, véase las declaraciones de Adolfo Córdova en Martuccelli 2012: 67, 71.

${ }^{74}$ Agrupación Espacio 1947.
} 
de repertorio: en pintura, del modelo parisino al indigenismo y, en arquitectura, del beaux arts al «barroquismo colonialista». Mientras que el indigenismo había producido imágenes caricaturizadas del hombre andino, el neocolonial reflejaba la «tragedia y mentira de los neoestilos». ${ }^{75}$ El discurso de Espacio tomó así un tono moralizador. De la misma forma en que la pintura abstracta renunciaba a todo tema, los edificios funcionalistas, de fachadas geométricas, estaban libres de «mentiras» $y$ "colonialismo». ${ }^{76}$

Espacio se opuso tanto al empleo de modelos coloniales para la arquitectura contemporánea como a los procesos de reforma y "puesta al día» de la arquitectura colonial. Esto se desprendía naturalmente del ideario funcionalista, pero implicaba, además, una directa oposición contra las reformas ejecutadas por arquitectos de la generación anterior. Los miembros del grupo afirmaron ser «más tradicionalistas» que los arquitectos neocoloniales, pues lo importante no era citar o actualizar el pasado, sino conservarlo. En ello se dijeron continuadores de las ideas del teórico inglés John Ruskin, para quien modernizar la arquitectura del pasado era tan absurdo como «revivir un muerto». ${ }^{77}$

Adicionalmente, las «máquinas racionales» responderían mejor que sus antecesores a problemas sociales y de vivienda. El neocolonial, en particular, habría prestado excesiva atención a repertorios e ideologías colonialistas, desatendiendo el factor social. ${ }^{78}$ Esta retórica sociológica fue característica del funcionalismo en otros países, y en Perú estuvo vinculada al discurso progresista del gobierno de José Luis Bustamante y Rivero (1945-1948). Dicha administración promovió una imagen progresista y dio su venia al plan piloto. ${ }^{79}$ Así, si en décadas anteriores los proyectos de modernización urbana se centraron en el asunto de los estilos, Espacio

75 Jara 1949.

${ }^{76}$ Agrupación Espacio 1948.

77 Pérez Barreto 1948; Agrupación Espacio 1950; Córdova, Pérez Barreto y Williams 1950.

${ }^{78}$ Miró Quesada 1950.

${ }^{79}$ El diario progresista La Nación tuvo colaboraciones de miembros de Espacio como Salazar Bondy, Jorge Eduardo Eielson y Szyszlo. Existe un eco entre la «Expresión de principios» y el «Manifiesto del Sindicato de Artes Plásticos y Afines» (Kusunoki 2011: 57). 
cargó de un tenor moralista y político los debates arquitectónicos, postulando su propuesta como progresista y las anteriores como conservadoras. ${ }^{80}$ Harth-terré fue un importante interlocutor para los promotores del funcionalismo. Desde fines de los treinta había cuestionado públicamente la arquitectura de "fierro y economía», no solo por su «negación de lo espiritual» sino ante todo porque sus edificios resultaban «ajenos» y «alardes del comercio y la propaganda». ${ }^{81}$ Luego, en 1947, año de la aparición del manifiesto de la agrupación, criticó las tendencias arquitectónicas «snobistas»e «iconoclastas». ${ }^{82}$

También en 1947 publicó una réplica a la «Expresión de principios». Ante todo, afirmó compartir la intención de Espacio: «modernizar nuestra arquitectura». Para él, sin embargo, la modernidad no era un asunto «técnico», sino algo del «espíritu». ${ }^{83}$ Por otro lado, señaló que era falso que el funcionalismo no tuviera una tradición, pues, aunque no lo reconociera, seguía la línea de la arquitectura industrial europea del siglo XIX. La idea de una forma sin historia era falaz, y el funcionalismo era una de las tantas "exóticas corrientes» o modas que pecaba, además, por no tener vínculo con «lo propio». ${ }^{84}$ Tal ilusión era producida por la "encrucijada» de los tiempos de posguerra y hacía aún más necesario buscar un estilo con identidad para el Perú. ${ }^{85}$

Estos debates estéticos no tuvieron tanta repercusión como la polémica en torno al patrimonio arquitectónico iniciada por Espacio a fines de los

${ }^{80}$ La idea de una «revolución» de la que hablaron algunos miembros de Espacio no implicó para otros una toma de posición política, sino una afirmación individualista por medio de la creatividad. En adelante, la segunda postura fue la oficial del grupo, lo cual alejó de Espacio a miembros con preocupaciones políticas explícitas, como Salazar Bondy. Véanse Ludeña 2004: 176; y Kusunoki 2011: 58. Sobre las formas de planificación urbana del funcionalismo, véase Holston 1989: 41 y ss.

${ }^{81}$ Harth-terré 1937 y 1946.

${ }^{82}$ Harth-terré 1947a: 15 y ss. En un artículo, Harth-terré caracterizó las campañas de Espacio como mero «autobombo», y puso en duda la convicción de sus miembros (Córdova, Pérez Barreto y Williams 1950).

${ }^{83}$ Harth-terré $1947 b$.

${ }^{84} \mathrm{Ib}$. La historiografía internacional ha cuestionado la idea de «no referencia» del funcionalismo (Elliot 2009: 128-146).

${ }^{85}$ Harth-terré 1947a: 1-2, 7. 
cuarenta. Cabe recordar que el que una reforma implicara la destrucción de edificios y espacios tradicionales no habría generado mayor controversia pocos ańos atrás. ${ }^{86} \mathrm{Al}$ comentar la reforma de los edificios que daban al paseo de Los Descalzos de 1943 diseñada por Carlos Morales Machiavello, un escritor afirmó que esta ayudaría a «devolver el aspecto típico» a dicho espacio. ${ }^{87} \mathrm{Si}$ bien existió desde inicios de siglo una valoración importante de la arquitectura colonial, esta estuvo restringida a ciertas iglesias y residencias, dejando de lado construcciones coloniales «menores».

La polémica en torno a la demolición del portal de Botoneros marcó un punto de inflexión en este consenso tácito. En 1947, un periodista de El Comercio se opuso a la aún no iniciada reforma de dicho portal, al que describió como una "auténtica obra colonial y un indicio al alcance de la mano para comprender épocas desaparecidas de Lima». ${ }^{88}$ Ese mismo año Rafael Marquina, miembro de la comisión evaluadora del concurso de reforma de 1939, envió una carta de reclamo al Concejo Municipal argumentando que el fallo del jurado había sido seguir el diseño de Morales y Montagne para remodelar dicho portal, pues lo preservaba. ${ }^{89}$ En su condición de miembros de la Sociedad Peruana de Historia, Ella Dunbar Temple y Pedro M. Benvenutto Murrieta expresaron también su descontento al Concejo. ${ }^{90}$ Pese a la polémica, Botoneros fue demolido. Adicionalmente, el Concejo proyectó en 1950 la demolición de los dos edificios coloniales aledańos al palacio de gobierno y el levantamiento en su lugar de dos plazuelas. Las plazuelas Pizarro y Castilla, pensadas para realzar la perspectiva del amplio patio del palacio, recibirían además

${ }^{86}$ Los debates sistemáticos sobre conservación de monumentos históricos eran relativamente recientes en los cuarenta. Si bien la primera conferencia internacional sobre el tema fue realizada en Atenas en 1931, esta reunió solo a países europeos. La segunda, efectuada en Venecia en 1964, contó ya con la presencia de países no europeos: Túnez, México y Perú (Choay 1992: 10).

87 «Reconstrucciones acertadas» 1943.

88 «Motivos del ambiente» 1947.

${ }^{89}$ Marquina expresó también su reclamo a la Sociedad de Arquitectos, contando con el apoyo de Miró Quesada Garland y Morales Machiavello (Tarazona 1971: 31).

${ }^{90}$ Para un recuento, véase «Sociedad Peruana de Historia» 1950. 
sendas esculturas de los personajes históricos que les daban nombre. ${ }^{91}$ Una vez más, Marquina, por un lado, y los miembros de la Sociedad Peruana de Historia, por otro, se manifestaron en contra. Según el comunicado de la Sociedad, el proyecto atentaba contra el carácter «estético y nacionalista» de la plaza, la cual alojaba el «espíritu de la nación». ${ }^{92}$

Aunque publicitados, estos reclamos no contaron con la claridad pedagógica ni con la frecuencia mediática de los artículos y caricaturas de la Agrupación Espacio. En 1951, Eduardo Neira y Luis Miró Quesada publicaron sendos artículos contra "las plazuelas de la plaza». ${ }^{93}$ Ambos concordaban en que el sentido original de la plaza de Armas consistía en ser un «reciento cerrado" que sorprendía al peatón que entraba por sus angostas calles. El edificio Oeschle, el patio del palacio de gobierno y el retiro de los nuevos portales eliminaron tal perspectiva. Según Neira las "plazitas» serían «el golpe de gracia» contra la plaza. Además, que la Municipalidad siga proyectando plazuelas con monumentos era una anacrónica "falta de sentido social», pues una ciudad con los problemas urbanos de Lima requería "parques y no plazoletas».

Una caricatura de Adolfo Córdova (Fig. 12) hizo más explícitos estos argumentos. La imagen presentaba cuatro versiones del centro histórico, cada una figurada como un tablero de ajedrez en alusión al diseño original «en cuadrícula» de dicho espacio. Al centro de cada tablero, la plaza era acechada por un caballo (la escultura ecuestre de Francisco Pizarro) y un alfil (el monumento a Ramón Castilla). La variación de posiciones de las piezas parodiaba los movimientos planificados para las esculturas: en efecto, la de Pizarro sería resituada en una de las plazuelas luego de haber estado en el patio de la catedral, ${ }^{94}$ y la de Castilla vendría desde la plazuela de la iglesia La Merced. A entender de Córdova, las reformas de la plaza parecían responder más a un «juego» de emplazar y mover monumentos que a un plan urbano. En última instancia, el único efecto

\footnotetext{
91 Sobre el proyecto, véase Neira 1951.

92 «Corónica: defensa del patrimonio» 1949-1950.

${ }^{93}$ Neira 1951; Miró Quesada 1951.

${ }^{94}$ Sobre el recorrido de la escultura de Pizarro, Varón 2006.
} 


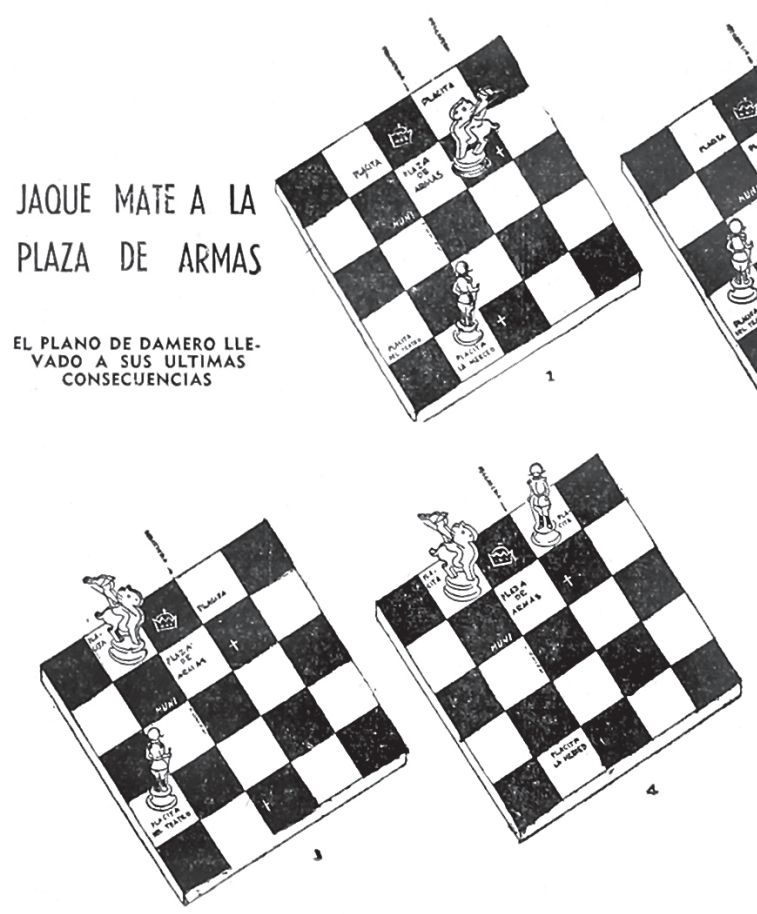

\begin{abstract}
(A propósito de la creación do dos placitos para trasladar allí monumentos). Los españoles hicicron Lima con el trazo do damero y los republicanos, quienes siempre nos ha gusquienes siempre nos ha gus-
todo aquello de mover los monumentos, hemos encontrodo ahora que es más interesonte jugar al ajedrex en damero colonial:

Dib. 1.- Juegan las blancas y dan mate a la Plaza de Armas en tres jugadas. Alfil Monumento a Ramón CastiIIo - Cobollo (Momumento a Francisco Pizarro).

Dib. 2.- Estratégico movimiento del Alfil Castilla, que amenaza la casilla de

Pescaderia.

Dib. 3. Caballo Pizarro oeupa casilla Canesso. Dib. 4.- Alfil Castilla ocupo casilla Pescadería. Jaque Mate.
\end{abstract}

Figura 12. Adolfo Córdova, "Jaque mate a la Plaza de Armas» (Neira 1951).

logrado sería un «jaque mate» contra lo que quedaba de la composición original de la plaza de Armas.

Las caricaturas de Córdova y los artículos de otros miembros de Espacio lograron evitar que se construyera la plazuela Castilla, aunque no la Pizarro. ${ }^{95}$ El alcance de las campañas de Espacio fue tal que Harthterré solicitó y logró temporalmente que su columna sea retirada de $E l$ Comercio cuando ahí se publicara una mordaz caricatura del «jarterrosimo» (Fig. 3). ${ }^{96}$ En última instancia, si bien el plan piloto no llegó a ser implementado en lo referido al centro histórico, los alegatos de Espacio

${ }^{95}$ Comunicación electrónica con Adolfo Córdova, 2 de mayo de 2016. ${ }^{96} \mathrm{Ib}$. 
contra el neocolonial y contra la plaza sí hicieron eco entre el gremio de arquitectos. ${ }^{97} \mathrm{El}$ neocolonial, por un lado, dejó de ser el estilo predilecto para encargos oficiales — rol cedido al funcionalismo - y tuvo solo tiempo después un tímido resurgir en la arquitectura residencial. ${ }^{98}$ La plaza, por otro, definió su condición de espacio turístico, a la vez que el centro histórico dejó de alojar las sedes políticas y financieras más importantes y los centros culturales y sociales más visitados, como lo propuso Espacio. ${ }^{99}$

Al consolidarse el lugar privilegiado del funcionalismo, los juicios de valor de los arquitectos afiliados al mismo influyeron no solo en las percepciones del periodo, sino también en la historiografía posterior. Hasta el presente, tanto entre arquitectos como entre historiadores de la arquitectura — muchos de ellos formados como arquitectos - tanto la plaza reformada como el estilo en que fue diseñada son interpretados como incomprensibles y «anacrónicos». Esta situación de desprestigio ha llevado a subestimar los aportes de arquitectos de la primera mitad del siglo XX a los debates sobre modernización urbana y patrimonio arquitectónico.

Harth-terré estuvo muy interesado en ambos temas. En un ensayo escrito tiempo después de su polémica reforma de la plaza, pero haciendo clara alusión a ella, afirmó que todo monumento ha pasado por múltiples refacciones, las cuales devienen parte de su «unidad histórica». Incluso los portales neocoloniales, sostuvo, adquirirían algún día el sello de «históricos, intangibles y tradicionales» y tendrían que ser "defendidos de nuevos modernizantes». ${ }^{100}$ Aunque controvertidas, sus afirmaciones constituyeron un agudo contrapunto a versiones del funcionalismo como la del plan piloto, según el cual la arquitectura colonial debía ser conservada intangible o como aislado "pozo de luz», y la arquitectura historicista (sea beaux arts o neocolonial) podía ser demolida o abandonada como si no tuviera valor histórico por sí misma.

${ }^{97}$ El funcionalismo fue la tendencia predilecta de los gobiernos de Bustamante y Rivero, y Manuel A. Odría (Ludeña 2004: 157, 180).

98 Rodríguez Cobos 1983: 65-73.

99 Ludeña 2009: 154.

${ }^{100}$ Harth-terré 1971: 18-22. 


\section{BIBLIOGRAFÍA}

Abad, Teresa y Samuel Cárdenas. 1975. Evolución histórica del espacio urbano de la Plaza Mayor de Lima. Tesis de bachillerato en Arquitectura. Lima: Universidad Nacional de Ingeniería.

"Adaptación del arte precolombino a la casa de campo de línea contemporánea». 1940. El Arquitecto Peruano. Núm. 31, febrero: [29].

Agrupación Espacio. 1947. «Expresión de principios de la "Agrupación Espacio"». El Comercio. 15 de mayo: 3-4.

. 1948. «Colabora la Agrupación Espacio. Del arte contemporáneo en el Perú. Tradición y contemporaneidad». El Comercio. 18 de marzo, edición de la tarde: 8 .

. 1950. «Colabora la Agrupación Espacio. Un problema planteado de cabeza». El Comercio. Suplemento dominical, 22 de enero: I.

Alegre, Roy Luis. 2001. «La Agrupación Espacio en El Comercio»: aproximaciones al proceso moderno en el Perú. Tesis de maestría en Arquitectura. Lima: Universidad Nacional de Ingeniería.

«Alineamiento de la Plaza de Armas». 1938. El Arquitecto Peruano. Núm. 13, agosto: [11].

Álvarez, Syra. 2006. La formación en arquitectura en el Perú: Antecedentes, inicios y desarrollo hasta 1955. Lima: Universidad Nacional de Ingeniería. Amaral, Aracy. 1994. "La invención de un pasado». En Arquitectura neocolonial: América Latina, Caribe, Estados Unidos. São Paulo: Fondo de Cultura Económica, 11-16.

Bianco, Mario. 1950. «Respetamos la zonificación urbana». Espacio. Núm. 4: 11 .

Callirgos, Juan Carlos. 2007. Reinventing the City of Kings: Postcolonial Modernization of Lima, 1845-1930. Tesis de doctorado en Historia. Gainesville: University of Florida.

Carrera, Eudocio. 1954. La Lima criolla de 1900 (corregida y aumentada). Lima: Sanmarti.

Castillo, Teófilo. 1912. «Evocación feliz». Ilustración Peruana. Núm. 149, 25 de setiembre.

Centurión Herrera, Enrique. 1924. El Perú actualy las coloniales extranjeras. Bérgamo: Istituto Italiano d'Arti Grafiche.

"Concurso para la reconstrucción de los inmuebles de la Plaza de Armas». 1939. El Arquitecto Peruano. Núm. 26, setiembre: [49-56]. 
Contreras, Carlos y Marcos Cueto. 2010. Historia del Perú contemporáneo: desde las luchas por la independencia hasta el presente. Lima: Instituto de Estudios Peruanos y Pontificia Universidad Católica del Perú.

Córdova, Adolfo. 1949. «Colabora la Agrupación Espacio. El jarterrorismo, la arquitectura y el amor». El Comercio. 15 de diciembre, edición de la tarde: 8.

Córdova, Adolfo, Samuel Pérez Barreto y Carlos Williams. 1950. «Con lámpara o sin lámpara, en busca de arquitectura». El Comercio. Suplemento dominical, 5 de febrero: I.

«Corónica: defensa del patrimonio histórico y artístico». 1949-1950. Documenta. Año 2, núm. 1: 883-889.

Choay, Françoise. 2007. La alegoría del patrimonio. Traducción de María Bertrand Suazo. Barcelona: Gustavo Gili.

«Documentos municipales. Obras». 1938. Boletín Municipal. 31 de julio: 22. «El nuevo palacio arzobispal». 1911. Variedades. Núm. 175, 8 de julio: 812-814.

«El Palacio Arzobispal». 1924. Ciudad y Campo y Caminos. Núm. 1, junio: 26.

«El voraz incendio de anoche». 1923. El Comercio. 4 de noviembre: 10.

Elguera, Federico. 1901. Memoria de la Municipalidad de Lima. Lima: Librería e Imprenta Gil.

. 1903. "Construcciones urbanas». El Comercio. 31 de octubre.

. 1906. Memoria de la Municipalidad de Lima. Lima: Librería e Imprenta Gil.

. 1924. «El nuevo palacio municipal». Ciudad y Campo y Caminos. Núm. 1, julio: 7.

Elliot, Bridget. 2009. «Modern, Moderne, and Modernistic: Le Corbusier, Thomas Wallis and the Problem of Art Déco». En Disciplining Modernism. Nueva York: Palgrave Macmillian, 128-146. Disponible en: <http://dx.doi.org/10.1057/9780230274297_8>.

«Embellecimiento de la Plaza de Armas». 1938. Boletín Municipal. 30 de setiembre: 29.

«Exposición de las labores realizadas por las Oficinas Municipales, presentada al Concejo por el Sr. Alcalde D. Eduardo Dibós Dammert». 1938. Boletín Municipal. 31 de octubre: 24 . 
Flaherty, George. 2013. «Mario Pani’s Hospitality. Latin America through Arquitectura/México». En Latin American Modern Architectures. Ambiguous Territories. Nueva York: Routledge, 251-269.

García Bryce, José. 1959. "Arquitectura peruana». Boletín. Sociedad de Arquitectos del Perú. Núm. 7, abril-junio.

1980. La arquitectura en el virreinato y la república. Lima: Editorial Juan Mejía Baca.

Gorelik, Adrián. 2010. La grilla y el parque. Espacio público y cultura urbana en Buenos Aires, 1887-1936. Buenos Aires: Universidad Nacional de Quilmes.

Gutiérrez, Ramón. 1998. "Las plazas americanas, de la ilustración a la disgregación». En La plaza en España e Iberoamérica. El escenario de la ciudad. Madrid: Museo Municipal de Madrid, 121-128.

Harth-terré, Emilio. 1937. «¿Qué cosa es el funcionalismo?». El Arquitecto Peruano. Núm. 2, setiembre: 35.

. 1945. "Análisis de una arquitectura peruana contemporánea». El Arquitecto Peruano. Núm. 92, marzo: [33-35].

. 1946. «Le Corbusier, predicador infatigable. Comentario bibliográfico a su último libro». El Arquitecto Peruano. Núm. 111, octubre: [33]. . 1947a. Por una arquitectura contemporánea que sea nuestra. Lima: Editorial Etinsa.

. 1947b. «Espacio». El Comercio. 18 de junio, edición de la tarde: 8. . 1971. Mi «carta de Lima». Lima: Editorial Universitaria.

Harth-terré, Emilio y Alberto Márquez Abanto. 1959. «Las bellas artes en el virreinato del Perú. Nota para una historia del balcón en Lima». Revista Archivo Nacional del Perú. Vol. XXIII, entrega II: 400-468.

Hayakawa, José Carlos. 2010. Restauración en Lima: Pasos y contrapasos. Lima: Universidad de San Martín de Porres.

Holston, James. 1989. The Modernist City. An Anthropological Critique of Brasilia. Chicago: The University of Chicago Press.

Jara, César de la. 1949. «Colabora la Agrupación Espacio: Tragedia y mentira de los neoestilos». El Comercio. 1 de abril, edición de la tarde: 8

Kahatt, Sharif. 2015. Utopias construidas. Las unidades vecinales de Lima. Lima: Pontificia Universidad Católica del Perú.

Kidney, Walter. 1987. The Architecture of Choice. Eclecticism in America 1880-1930. Nueva York: George Braziller. 
Kusunoki, Ricardo. 2011. «Szyszlo y la batalla por la abstracción (19471955)». En Szyszlo. Lima: Museo de Arte de Lima, 54-71.

«La acusación de vetusto a un monumento urbano es una máscara a nuestra desidia o a nuestra impasible actitud ante la historia». 1946. El Comercio. 10 de diciembre: 3 .

«La hoja del urbanismo. Perú». 1949. El Arquitecto Peruano. Núm. 141, abril: [35].

«La Lima que veo venir». 1924. Ciudad y Campo y Caminos. Núm. 2, agosto-setiembre: 13-14.

«La Plaza San Martín y la edificación de sus contornos en el corazón de la ciudad». 1930. Ciudad y Campo y Caminos. Núm. 47.

«La reconstrucción del Palacio Municipal en la Plaza de Armas. ¿Cree usted que la Municipalidad debe retornar a su antiguo solar?». 1938. Boletín Municipal. 31 de agosto: 33-37.

«La regia mansión de los marqueses de Torre Tagle». 1921. Variedades. Núm. 700, 30 de julio.

«La tendencia moderna en los edificios públicos». 1939. El Arquitecto Peruano. Núm. 23, junio: [29-32].

Lizárraga, Nancy y Luis Benavente (eds.). 1982. Emilio Harth-Terré. Catálogo Bio-Bibliográfico. Lima: Universidad de Lima.

Lozoya, Johanna. 2010. Las manos indígenas de la raza española. El mestizaje como argumento arquitectónico. Ciudad de México: Dirección de Publicaciones del Concejo Nacional para la Cultura y las Artes.

Ludeña, Wiley. 2004. Tres buenos tigres. Piqueras - Belaunde - La Agrupación Espacio. Vanguardia y urbanismo en el Perú del siglo XX. Lima: Ediciones Urbes.

.2009. Urbanismo dixit. Inquisiciones. Quito: Organización Latinoamericana y del Caribe de Centros Históricos.

Majluf, Natalia. 1994a. Escultura y espacio público. Lima, 1850-1879. Lima: Instituto de Estudios Peruanos.

. 1994b. «El indigenismo en México y Perú: Hacia una visión comparativa». En Arte, historia e identidad en América: Visiones comparativas. Ciudad de México: Universidad Nacional Autónoma de México, 610-628.

Majluf, Natalia y Luis Eduardo Wuffarden. 2013. Sabogal. Lima: Museo de Arte de Lima. 
Martuccelli, Elio. 2012. Conversaciones con Adolfo Córdova. Lima: Universidad Nacional de Ingeniería.

Mejía, Víctor. 2013. Prefiguración de la Plaza San Martín y su monumento (1889-1921). Tesis de maestría en Historia del Arte. Lima: Pontificia Universidad Católica del Perú.

«Memoria presentada al Concejo Provincial de Lima por el señor Alcalde don Eduardo Dibós Dammert, correspondiente al año 1937». 1938. Boletín Municipal. 31 de enero: 8.

Miró Quesada Garland, Luis. 1948a. «Colabora la Agrupación Espacio. La feria de los balcones». El Comercio. 11 de noviembre, edición de la tarde: 8 .

. 1948b. «Colabora la Agrupación Espacio. Congestión urbana». El Comercio. 23 de diciembre, edición de la tarde: 8 .

. 1950. «Problemas urbanos aquí y ahora». El Comercio. Suplemento dominical, 12 de marzo: I.

. 1951. «Reformas urbanas para Lima: las plazoletas de la Plaza de Armas». Espacio. Núm. 7, mayo: 2.

«Modelo Lima. Modelo Cuzco». 1928. Ciudad y Campo y Caminos. Núm. 37, enero-febrero: 18-19.

«Motivos del ambiente. Los viejos portales desaparecen». 1947. El Comercio. 21 de agosto, edición de la tarde: 3 .

Muñoz, Fanni. 2001. Diversiones públicas en Lima 1890-1920: la experiencia de la modernidad. Lima: Red para el Desarrollo de las Ciencias Sociales en el Perú.

Neira, Eduardo. 1949. «Colabora la Agrupación Espacio. Concurso arquitectónico». El Comercio. 15 de diciembre, edición de la tarde: 8.

. 1951. «Las plazas de la Plaza de Armas». El Comercio. 17 de mayo, edición de la tarde: 3 .

«No. 3 Modelo "Trujillo". No. 4 Modelo "Cañete”». 1928. Ciudady Campo y Caminos. Núm. 39, mayo: 12-13.

«No. 5 Modelo "Puno". No. 6 Modelo "Huancayo"». 1928. Ciudady Campo y Caminos. Núm. 40, junio-julio: 14-15.

«Nueva Avenida 28 de Julio». 1906. Prisma. Núm. 17, julio: 26.

«Nuevo palacio arzobispal proyecto». 1909. Ilustración Peruana. Núm. 23, 2 de diciembre: 545 . 
Oficina Nacional de Planeamiento y Urbanismo. 1949. Plan Piloto de Lima. Lima.

«Parque Ayacucho en la Plaza de Armas. Gran lugar de espectáculo y atracciones de completa novedad». 1924. Ciudad y Campo y Caminos. Núm. 3, octubre: 9.

«Parques en la Plaza de Armas». 1901. El Comercio. 15 de mayo, edición de la tarde: 1.

Passini, Michela. 2013. La fabrique de l'art national: Le nationalisme et les origins de l'histoire de l'art en France et en Allemagne 1870-1933. París: Éd. de la Maison des sciences de l'homme.

Pérez Barreto, Samuel. 1948. «Colabora la Agrupación Espacio. Tradición y anti-tradición». El Comercio. 29 de abril, edición de la tarde: 8 .

Pinillos, Gladys y Noris Pinillos. 1982. Harth-terré, arquitecto. Tesis de bachillerato en Arquitectura. Lima: Universidad Nacional de Ingeniería. «Plazo para la reconstrucción de los inmuebles con frente a la Plaza de Armas». 1939. Boletín Municipal. Marzo: 4-5

«Por el embellecimiento de Lima». 1924. Mundial. Núm. 195, 8 de febrero: [6].

Port, M. H. 1995. Imperial London. Civil Government Building in London 1850-1915. New Haven: Yale University Press.

«Proyecto para la reconstrucción de la Plaza de Armas. Portal izquierdo en estudio. Portal derecho en obras». 1940. El Arquitecto Peruano. Núm. 35, junio: [24-25].

Ramón, Gabriel. 1999. La muralla y los callejones. Intervención urbana y proyecto politico en Lima durante la segunda mitad del siglo XIX. Lima: PromPerú.

.2012. «De la Plaza Mayor a la Plaza de Armas: la política borbónica y el espacio urbano de Lima (1740-1820)». En Contextualizando la ciudad en América Latina. Quito: Ediciones Abyala-Yala, 287-327.

Ramos, Horacio. 2014. Destrucción y reinvención de la Plaza de Armas. Estilo neocolonial y modernización urbana en Lima, 1924-1954. Tesis de maestría en Historia del Arte. Lima: Pontificia Universidad Católica del Perú. «Reconstrucciones acertadas: Proyecto para las fachadas que dan al Paseo de los Descalzos». 1943. El Arquitecto Peruano. Núm. 73, agosto: [6] Riva-Agüero, José de la. 1934. «Invocación del doctor Riva-Agüero por la tradición de la Casa Consistorial». El Comercio. 9 de noviembre. 
Rodríguez Cobos, Luis. 1983. Arquitectura limeña. Paisajes de una utopía. Lima: Fondo Editorial Colegio de Arquitectos del Perú.

Salazar Bondy, Sebastián. 2002. Lima, la horrible. Concepción: Universidad de Concepción.

Sandoval, Ángel. 2014. «Del valle a las pampas: la expansión urbana de la ciudad de Lima en el sur (1954-1975)». Sintesis Social. Revista de Investigaciones Histórico Sociales. Núm. 5: 99-116.

San Cristóbal, Antonio. 1999. Teoría sobre la historia de la arquitectura virreinal peruana. Lima: Universidad Nacional de Ingeniería.

Sert, Josep Lluís y Paul Lester Wiener. 1948. «El Plan Piloto de Lima». El Comercio. 9 de diciembre, edición de la tarde: 5 .

«Sesión ordinaria del sábado 23 de marzo de diciembre de 1939». 1940. Boletín Municipal. 31 de marzo: 10.

«Sociedad Peruana de Historia». 1950. El Comercio. 30 de diciembre: 9. Tarazona, Manuel. 1971. «Arquitectos: Portales de piedra pudieron salvarse». 7 Días del Perú y del Mundo. Núm. 667, 16 de abril: 30-31.

Valdelomar, Abraham. 1916. «El proyecto Malachowsky». La Prensa. 11 de diciembre: 2 .

Vallejos, Rosa. 1997. «Piedras rodantes. Extraviados por décadas, reaparecen restos de los antiguos portales de Lima». Caretas. Ilustración Peruana. Núm. 1458, 27 de marzo: 42-44.

Varón, Rafael. 2006. «La escultura de Francisco Pizarro en Lima. Historia e identidad nacional». Revista de Indias. Núm. 236, enero-abril: 217-236. Velarde, Héctor. 1946. Arquitectura peruana. Ciudad de México: Fondo de Cultura Económica.

Villegas, Fernando. 2006. El Perú a través de la pintura y critica de Teófilo Castillo (1887-1922). Nacionalismo, modernización y nostalgia en la Lima del 900. Lima: Asamblea Nacional de Rectores.

Wuffarden, Luis Eduardo. 2011. "Itinerario de un artista integral». En Szyszlo. Lima: Museo de Arte de Lima, 28-52.

Fecha de recepción: 10/VIII/2015

Fecha de aceptación: 12/III/2016 